\title{
Expression and Gene Regulation Network of
}

NUDT21 in Lung Adenocarcinoma and Prediction of Anticancer Components of Pinellia Ternata Based on Data Mining

\author{
Yongli SITU ( $\nabla$ styl1987@126.com ) \\ Jinan University \\ Li-na LONG \\ Jinan University \\ Hai-jian LI \\ Guangdong Second Provincial General Hospital \\ Zhi-xin FANG \\ Guangdong Second Provincial General Hospital \\ Hong NIE \\ Jinan University
}

\section{Research}

Keywords: Lung adenocarcinoma, NUDT21, gene regulation network, data mining, Pinellia ternata

Posted Date: April 19th, 2021

DOI: https://doi.org/10.21203/rs.3.rs-411545/v1

License: (a) (i) This work is licensed under a Creative Commons Attribution 4.0 International License.

Read Full License 


\section{Abstract \\ Background}

NUDT21 belongs to NUDT families, which is thought to play an essential role in cancer growth and progression in recent years. Abnormal NUDT21 expression is closely related to lung adenocarcinoma (LUAD). However, the expression level, gene regulation network, and prognostic value of NUDT21 in LUAD remain unclear. Besides, the active compounds of Pinellia ternata against LUAD are still not clear yet. Therefore, an in-depth study of the expression and gene regulation network of NUDT21 is of great theoretical significance and clinical demand for discovering new targets and strategies for the treatment of LUAD and the further improvement of the therapeutic effect of LUAD. Also, the targeted NUDT21 active ingredients of Pinellia ternata were sought to provide a theoretical basis for its clinical application in the treatment of LUAD.

\section{Methods}

A variety of online analysis tools were used in this study, including cBioPortal, ONCOMINE, GeneMANIA, GEPIA, Metascape, UALCAN, LinkedOmics, Metascape, TIMER, TRRUST, The Human Protein Atlas, TCMSP, and AutoDock Vina.

\section{Results}

The levels of transcription and expression of NUDT21 were significantly increased in patients with LUAD. Gene altered of NUDT21 was up to $12 \%$ in LUAD patients. However, the promoter methylation level of NUDT21 in LUAD was lower compared to normal human. LUAD patients' survival with the low expression level of NUDT21 was better prognostic value than LUAD patients with high expression level. Forty-eight nodes and 572 edges were found in the PPI network constructed with NUDT21 and its neighboring genes. Regulatory region DNA binding, transcription regulatory region DNA binding, and regulatory region nucleic acid binding were the primary function of NUDT21 and its neighboring genes. The KEGG pathway of NUDT21 and its neighboring genes were mainly involved in the apelin signaling pathway, PI3K-Akt signaling pathway, and axon guidance. Our results showed that DNMT1, HDAC1, and MYC were the critical transcription factor targets involved in the network of NUDT21 and its neighboring genes. We also found that CDK1, ATM and PLK1 were main kinase targets in the NUDT21 kinase-target network. The NUDT21 miRNA-target network was associated with MIR-302C, MIR-9, and MIR-330. Moreover, the expression of NUDT21 was positively related to the infiltration of CD $8+T$ cells, macrophages, neutrophils and dendritic cell. 13 active compounds of Pinellia ternata were retrieved from the TCMSP. Among them, baicalein was the best combination with NUDT21.

\section{Conclusions}


Our results revealed the expression and potential regulatory network of NUDT21 in LUAD, laying a foundation for further research on the role of NUDT21 in cancer. Furthermore, we offer new therapeutic targets and prognostic biomarkers for the reference. Finally, we provide potential therapeutic drugs from traditional Chinese medicine in the treatment of LUAD.

\section{Introduction}

Lung cancer is one of the deadliest malignancies in the world [1]. According to statistics, the number of lung cancer deaths was as high as 1.8 million, accounting for $18.4 \%$ [2]. Moreover, accounts for about $85 \%$ of lung cancer are non-small cell lung cancer, three histological subtypes that include squamous carcinoma, large cell undifferentiated carcinoma, and adenocarcinoma [3]. Among them, lung adenocarcinoma (LUAD) is the most common form of lung cancer. The pathogenesis of LUAD is extraordinarily complex and has not been fully elucidated. Studies have shown that many factors were involved in the development of LUAD, including diet, smoking,and genetic susceptibility[4-6]. Treatment for LUAD has progressed from the initial surgery, radiotherapy and chemotherapy to molecular-targeted therapy and immune-targeted therapy $[7,8]$. The innovations in the treatment of LUAD might significantly prolong the overall survival benefit of patients, but the survival prognosis for LUAD is still low. Part of the reasons for this mainly was associated with unknown target localization, difficulty in early diagnosis, high risk of cancer recurrence and high rate of early metastasis [9]. However, the discovery of various subtypes of lung cancer targets and the introduction of targeted therapy has changed the prognosis of patients with lung cancer by incorporating tumor genotyping into treatment decisions [10]. The results from the European EUHER2 showed that non-small-cell lung cancer patients, a known HER2 exon-20 insertion, treated with HER2-targeted drugs had established an excellent therapeutic effect on lung cancer [11]. Therefore, targeted therapy is expected to become the crucial methods of treating LUAD in the future, and bring good news for patients with LUAD.

NUDT21, as a member of NUDT families, that existed in nearly all organisms. And also is a tumor suppressor gene in the progression of cancer [12]. To date, its biological function remains unclear. NUDT21 as mRNA precursor 30-end modification factor mainly regulated 30UTR shortening. It participated in the normal physiological process of proliferation, differentiation and apoptosis in cells [13]. Previous studies had found that NUDT21 played an essential role in cancer growth and progression $[14,15]$. NUDT21 could inhibit various tumor growths, including glioblastoma, breast cancer, and cervical cancer [16-18]. However, the overexpression of NUDT21 was found in multiple cancers, including hepatocellular carcinoma, and leukemia $[19,20]$. However, we found that the overexpression and gene regulation network of NUDT21 in patients with LUAD by clinical trial data integration. Therefore, NUDT21 may be potential therapeutic targets and prognostic biomarkers for patients with LUAD.

Pinellia ternata, a plant of the Araceae has been used with its dried tuber as a drug in China for thousands of years. Pinellia ternata properties were spicy, warm, toxic, return to the spleen, stomach, and lung meridian. It had been documented by the Chinese Pharmacopoeia (2015 edition) as a commonly used Chinese medicine for the treatment of infection, inflammation, cough, and vomiting [21, 22]. 
Excepted for the pharmacological effects of anti-asthmatic, anti-tussive, anti-inflammatory anti-emetic, and sedative-hypnotic, in recent years, more and more studies have found that pinellia ternata has a therapeutic effect on various cancer $[23,24]$. To date, few studies have reported whether Pinellia ternata have potential therapeutic effects on LUAD.

In this study, to identify the overexpression and gene regulation network of NUDT21 in LUAD, we used the Cancer Genome Atlas (TCGA) and various public databases to explore the expression and differences of NUDT21 in LUAD patient. Moreover, we also explore the potential active components of Pinellia ternata in the treatment of LUAD by using network pharmacology and molecular docking methods. Finally, we hope that this approach will provide a new idea for the target treatment of other disease and screen the potential active ingredients of Pinellia ternata as a potential new drug against LUAD.

\section{Materials And Methods 1.1 Oncomine analysis}

Oncomine (www.oncomine.org) is a large tumor gene chip database that provides translational bioinformatics services for scientific researcher [25]. In our study, we registered platform of Oncomine database, and set the screening criteria as follow: (1) Gene: NUDT21; (2) Cancer type: lung adenocarcinoma; (3) Analysis type: cancer vs normal analysis; (4) Data type: mRNA; (5) Threshold setting conditions: $P=0.05$, fold change $=2$, and gene rank $=$ top $10 \%$. Student's $t$-test was used to analyze the difference of NUDT21 expression in LUAD.

\subsection{UALCAN analysis}

UALCAN (http://ualcan.path.uab.edu/analysis.html) is a portal for tumor subgroup gene expression and survival analyses [26]. We choose "Expression Analysis" module of UALCAN to analyst TCGA gene expression in this study, and the screening criteria were set as follow: (1) Gene: NUDT21; (2) Dataset: lung adenocarcinoma. (3) Threshold setting conditions: $P$-value cutoff $=0.05$. Student's $t$-test was used for comparative analysis.

\subsection{The Human Protein Atlas analyses}

The Human Protein Atlas (https://www.proteinatlas.org/) is a platform that provides cells, tissues and organs distribution information on all 24,000 human proteins and offers free public access. In this study, we analyzed the protein expression levels of NUDT21 in the lung tissue of patients with AULD.

\subsection{GEPIA analysis}

GEPIA (http://gepia.cancer-pku.cn/index.html) is a platform that is analyzing the RNA sequencing expression data of 9,736 tumours and 8,587 normal samples from the TCGA and the GTEx projects [27]. A variety of analytical methods were conducted in this study, including differential mRNA expression analysis, pathological stage analysis, and correlative prognostic analysis. We set the screening criteria as follow: (1) Gene: NUDT21; (2) Dataset: LUAD; (3) Threshold setting conditions: P-value cutoff $=0.05$. 
Student's $t$-test was used to analyze the expression of NUDT21 or pathological stage of LUAD. The Kaplan-Meier curve was used to analyze the prognosis of LUAD.

\section{5 cBioPortal analysis}

The cBioPortal (http://cbioportal.org) is an open-source for interactive exploration of multidimensional cancer genomics datasets that provide a visualization tool for studying and analyzing cancer genetic data [28]. In our study, genetic alterations and coexpression of NUDT21 were conducted from cBioPortal. The screening criteria were set as follow: (1) 230 samples of lung adenocarcinoma were analyzed; (2) mRNA expression z scores relative to all samples (log RNA Seq V2 RSEM) were obtained using a z score threshold of \pm 2.0. (3) Gene: NUDT21.

\subsection{STRING analysis}

STRING (https://string-db.org/cgi/input.pl) is a platform used to construct protein-protein interaction networks between target proteins [29]. This study builds the PPI network interaction by screening condition with medium confidence (0.4) and defined species as Homo sapiens.

\subsection{GeneMANIA analysis}

GeneMANIA (http://www.genemania.org) is a network for building protein-protein interactions (PPI), generating hypotheses about gene function, analyzing gene lists, and sequencing genes for function determination [30]. In this study, we constructed interaction networks for analyses the role of NUDT21 and the top 50 neighbor altered gene.

\subsection{Metascape analysis}

Metascape (https://metascape.org) is a simple and powerful gene function annotation and analysis tool that can help users apply the currently popular bioinformatics analysis methods to analyze batch genes and proteins to realize the knowledge of gene or protein function [31]. In our study, GO function and KEGG pathways enrichment analysis of NUDT21 and the top 50 neighbors' altered gene in LUAD were analyzed using Metascape.

\subsection{TRRUST analysis}

TRRUST is a manually curated database of human and mouse transcriptional regulatory networks that contain 8,444 and 6,552 TF-target regulatory relationships of 800 human TFs and 828 mouse TFs, respectively [32]. In this study, we tried to determine the key regulated factor of NUDT21 and the top 50 neighbors altered gene in LUAD by using TRRUST.

\subsection{LinkedOmics analysis}

LinkedOmics (http://www.linkedomics.org/) is a publicly available platform that includes multi-omics data from all 32 TCGA Cancer types [33]. It provides methods for analyzing and comparing cancer multiomics data within and across tumour types. In our study, kinase target enrichment, miRNA target enrichment, and genes differentially expressed in correlation with NUDT21 were conducted by using the 
"LinkInterpreter" module. The screening criteria set as follow: (1) a minimum number of genes (size) of 3; (2) cancer type: LUAD; (3) a simulation of 500; (4) search attribution: NUDT21 and the top 50 neighbors altered gene. (5) Target dataset: RNAseq (data type).

\subsection{Timer analysis}

TIMER (https://cistrome.shinyapps.io/timer/) is a comprehensive resource for systematical tumor immune analysis, including B cells, $C D 4+T$ cells, $C D 8+T$ cells, neutrophils, macrophages, and dendritic cells [34]. In our study, the correlation among clinical outcome and NUDT21 expression and the infiltration of immune cells was evaluated by "Survival module". The correlation between NUDT21 expression level and the infiltration of immune cells was assessed by "Gene module".

\subsection{TCMSP analysis}

TCMSP (http://lsp.nwu.edu.cn/tcmsp.php) is a pharmacology platform of Chinese herbal medicines that captures the relationships between drugs, targets and diseases [35]. In this study, the active ingredient of Pinellia ternata with $\mathrm{OB} \bowtie 30 \%$ and DL $₫ 0.18$ were obtained.

\subsection{Molecular docking analysis}

AutoDock Vina (http://vina.scripps.edu/) is an open-source program for doing molecular docking, which significantly improves the average accuracy of the binding mode predictions compared to AutoDock 4 [36]. Protein Database Bank (PDB, https://www.rcsb.org/) was used to acquire the protein crystal structure of target genes (NUDT21). 3D structures of active compounds were obtained from Pubchem (https://pubchem.ncbi.nlm.nih.gov/). Vina software 1.1.2 was used for molecular docking. Finally, the conformation with the lowest score was selected and plotted with PyMOL 2.4 for analysis.

\section{Results}

\subsection{NUDT21 expression in LUAD}

Compared the transcription levels of NUDT21 in lung tissue of patients with LUAD and normal human with the ONCOMINE, we found that the transcriptional levels of NUDT21 were significantly increased in patients with LUAD (Fig. 1). Moreover, these results were similar to Table 1. It showed that the mRNA level of NUDT21 was increased in LUAD than normal human. Yamagata N's dataset found that the transcriptional level of NUDT21 (fold change $=2.417$ and $p=0.008$ ) in LUAD was significantly increased [37]. Analogously, the transcriptional levels of NUDT21 in LUAD were significantly up-regulated in datasets of Okayama $\mathrm{H}$ (fold change $=1.841$ and $p=7.96 \mathrm{E}-17$ ) [38]. The fold change of NUDT21 expression in LUAD was $1.852(p=2.49 E-4)$ in Landi MT datasets [39]. 
Table 1

The mRNA levels of NUDT21 in different types of LUAD tissues and normal lung tissues at transcriptome level (ONCOMINE).

\begin{tabular}{|llllll|}
\hline TLR & Type & Fold change & Pvalue & ttest & Reference \\
\hline NUDT21 & LUAD & 2.417 & 0.008 & 2.966 & $(1)$ \\
& LUAD & 1.841 & $7.96 \mathrm{E}-17$ & 11.637 & $(2)$ \\
& LUAD & 1.852 & $1.72 \mathrm{E}-14$ & 8.884 & $(3)$ \\
\hline
\end{tabular}

Furthermore, we also compared the expression levels of NUDT21 in LUAD tissue and normal tissues with the UALCAN. Our results showed that the transcriptional levels of NUDT21 stratified based on gender and stages $(P=0.05)$ in LUAD tissues were significantly up-regulation (Fig. 2). The relative expression level of NUDT21 in LUAD tissues was evaluated with the GEPIA. The results showed that the relative expression level of NUDT21 was increased (Fig. 3). Besides, we compared the protein expression levels of NUDT21 in lung tissue of PAAD patients and normal people with the Human Protein Atlas. We found that the protein expression levels of NUDT21 were up-regulated in LUAD (Fig. 4). Then, the correlation between differential expression of NUDT21 and pathological stage in patients with LUAD was assessed. Our results showed a significant correlation between the expression of NUDT21 and pathological stage $(P=0.00106)$ (Fig. 5). Moreover, we evaluated the prognostic value of NUDT21 in LUAD patients with GEPIA. The results showed that LUAD patients' survival with the low expression level of NUDT21 was better prognostic value than LUAD patients with a high expression level of NUDT21 $(P=0.0029)$ (Fig. 6).

\subsection{Interaction network of NUDT21 alterations in LUAD}

The interaction network of NUDT21 on the molecular characteristics in LUAD was analysis. First, the genetic alteration of NUDT21 was evaluated with the TCGA. We found that NUDT21 were altered by $12 \%$ (Fig. 7A). However, the promoter methylation level of NUDT21 in LUAD was lower compared to normal human (Fig. 7B). Moreover, we found of NUDT21-neighboring genes (the 50 most frequently altered neighbor genes) that were altered at frequencies $>17 \%$ in LUAD (Table 2). The most frequent alterations among the NUDT21-neighboring genes were TTN2 (64.29\%), TP53 (60.71\%), and MUC16 (57.14\%). We then explore the potential interactions of NUDT21, and its neighboring genes, the PPI network analysis of them was established with STRING. We found that 48 nodes and 572 edges were obtained in the PPI network (Fig. 7C). We also found that regulatory region DNA binding, transcription regulatory region DNA binding, regulatory region nucleic acid binding, and regulation of homeostatic process were the primary function of NUDT21 and its neighboring genes with the results of GeneMANIA (Fig. 7D). 
Table 2

The top 50 of NUDT21 neighbor gene alterations in LUAD (cBioPortal).

\begin{tabular}{|llll|}
\hline Gene & Altered group & Unaltered group & P-value \\
\hline TTN2 & $18(64.29 \%)$ & $89(44.06 \%)$ & 0.0351 \\
\hline TP53 & $17(60.71 \%)$ & $90(44.55 \%)$ & 0.0802 \\
\hline MUC16 & $16(57.14 \%)$ & $75(37.13 \%)$ & 0.0353 \\
\hline FLG & $12(42.86 \%)$ & $50(24.75 \%)$ & 0.0398 \\
\hline RYR2 & $12(42.86 \%)$ & $70(34.65 \%)$ & 0.259 \\
\hline CSMD3 & $11(39.29 \%)$ & $70(34.65 \%)$ & 0.388 \\
\hline ZFHX4 & $10(35.71 \%)$ & $53(26.24 \%)$ & 0.202 \\
\hline LRP1B & $10(35.71 \%)$ & $58(28.71 \%)$ & 0.289 \\
\hline NELL1 & $8(28.57 \%)$ & $13(6.44 \%)$ & $1.220 \mathrm{e}-3$ \\
\hline ZNF804A & $8(28.57 \%)$ & $30(14.85 \%)$ & 0.0651 \\
\hline ZNF536 & $8(28.57 \%)$ & $34(16.83 \%)$ & 0.109 \\
\hline KMT2C & $8(28.57 \%)$ & $35(17.33 \%)$ & 0.123 \\
\hline KRAS & $8(28.57 \%)$ & $67(33.17 \%)$ & 0.400 \\
\hline USH2A & $8(28.57 \%)$ & $60(29.70 \%)$ & 0.548 \\
\hline FBN2 & $7(25.00 \%)$ & $25(12.38 \%)$ & 0.0709 \\
\hline DMD & $7(25.00 \%)$ & $26(12.87 \%)$ & 0.0822 \\
\hline ADAMTS12 & $7(25.00 \%)$ & $31(15.35 \%)$ & 0.154 \\
\hline COL11A1 & $7(25.00 \%)$ & $33(16.34 \%)$ & 0.190 \\
\hline SGIP1 & $6(21.43 \%)$ & $8(3.96 \%)$ & $2.894 \mathrm{e}-3$ \\
\hline KMT2D & $6(21.43 \%)$ & $13(6.44 \%)$ & 0.0167 \\
\hline ZNF521 & $6(21.43 \%)$ & $17(8.42 \%)$ & 0.0434 \\
\hline TRPS1 & $6(21.43 \%)$ & $19(9.41 \%)$ & 0.0635 \\
\hline LRP2 & $6(21.43 \%)$ & $20(9.90 \%)$ & 0.0754 \\
\hline $6(21.43 \%)$ & $22(10.89 \%)$ & 0.103 \\
\hline $6(21.43 \%)$ & $24(11.88 \%)$ & 0.135 \\
\hline TNR & $6(21.43 \%)$ & $25(12.38 \%)$ & 0.153 \\
\hline
\end{tabular}




\begin{tabular}{|c|c|c|c|}
\hline RELN & $6(21.43 \%)$ & 29 (14.36\%) & 0.235 \\
\hline RYR1 & $6(21.43 \%)$ & 29 (14.36\%) & 0.235 \\
\hline ANK2 & $6(21.43 \%)$ & 30 (14.85\%) & 0.258 \\
\hline HMCN1 & $6(21.43 \%)$ & 30 (14.85\%) & 0.258 \\
\hline FLG2 & $6(21.43 \%)$ & 31 (15.35\%) & 0.281 \\
\hline PAPPA2 & $6(21.43 \%)$ & 33 (16.34\%) & 0.330 \\
\hline CSMD1 & $6(21.43 \%)$ & 38 (18.81\%) & 0.455 \\
\hline FAT3 & $6(21.43 \%)$ & 38 (18.81\%) & 0.455 \\
\hline PCLO & $6(21.43 \%)$ & 40 (19.80\%) & 0.504 \\
\hline MUC17 & $6(21.43 \%)$ & 42 (20.79\%) & 0.553 \\
\hline CAMTA1 & $5(17.86 \%)$ & $2(0.99 \%)$ & $3.364 \mathrm{e}-4$ \\
\hline CHD9 & $5(17.86 \%)$ & $5(2.48 \%)$ & $3.088 \mathrm{e}-3$ \\
\hline OR2L2 & $5(17.86 \%)$ & $6(2.97 \%)$ & $5.177 e-3$ \\
\hline KPRP & $5(17.86 \%)$ & $8(3.96 \%)$ & 0.0121 \\
\hline FRMPD1 & $5(17.86 \%)$ & $9(4.46 \%)$ & 0.0171 \\
\hline USP29 & $5(17.86 \%)$ & $9(4.46 \%)$ & 0.0171 \\
\hline HERC2 & $5(17.86 \%)$ & $12(5.94 \%)$ & 0.0405 \\
\hline BCORL1 & $5(17.86 \%)$ & $13(6.44 \%)$ & 0.0513 \\
\hline $\mathrm{CDH} 7$ & $5(17.86 \%)$ & $13(6.44 \%)$ & 0.0513 \\
\hline TRPM6 & $5(17.86 \%)$ & $13(6.44 \%)$ & 0.0513 \\
\hline CCDC178 & $5(17.86 \%)$ & $14(6.93 \%)$ & 0.0636 \\
\hline CTNND2 & $5(17.86 \%)$ & $14(6.93 \%)$ & 0.0636 \\
\hline EPHA3 & $5(17.86 \%)$ & $14(6.93 \%)$ & 0.0636 \\
\hline HECW1 & $5(17.86 \%)$ & 15 (7.43\%) & 0.0775 \\
\hline
\end{tabular}

The GO function and KEGG pathways enrichment analysis of NUDT21 and the top 50 neighbors altered gene in LUAD was explored with the Metascape. Our results showed that the cellular components related to NUDT21 and its neighboring genes mainly involved in the extracellular matrix, apical plasma 
membrane, z disc, cell cortex, and postsynapse (Fig. 8A). Moreover, the release of sequestered calcium ion into cytosol by sarcoplasmic reticulum, cardiac chamber development, and protein tetramerization were the main biological processes (Fig. 8B). The molecular functions of NUDT21 and the top 50 neighbors altered gene were mainly included calcium ion binding, structure molecule activity, and protein domain specific binding (Fig. 8C). The KEGG pathway of NUDT21 and its neighboring genes were mainly involved in the apelin signaling pathway, PI3K-Akt signaling pathway, and axon guidance (Fig. 8D). We also found that non-small cell lung cancer recurrent, mixed tumor and sarcomatoid renal cell carcinoma was the manly disease related to NUDT21 and its neighboring genes (Fig. 8E).

\subsection{Transcription factor targets, kinase targets, and miRNA targets of NUDT21 in LUAD}

The potential transcription factor targets, kinase targets and miRNA targets of NUDT21 in LUAD were obtained in the database of TRRUST and LinkedOmics. The results showed that DNA (cytosine-5-)methyltransferase 1 (DNMT1), histone deacetylase 1(HDAC1), and v-myc myelocytomatosis viral oncogene homolog (MYC) were the key transcription factor targets involved in the network of NUDT21 and its neighboring genes ( $P \otimes 0.05)$ (Table 3 ). We also found that the top three kinase targets and miRNA targets of the NUDT21 network with the LinkedOmics (Table 4). Kinase CDK1, Kinase ATM and Kinase PLK1 were the top three targets in the NUDT21 kinase-target network (Pख0.00). The NUDT21 miRNA-target network was associated with (ATGTTAA) MIR-302C, (TAGCTTT) MIR-9, and (TGCTTTG) MIR-330 $(P \otimes 0.00)$.

Table 3

Key regulated factor of NUDT21 and the top 50 neighbor altered gene in LUAD (TRRUST).

\begin{tabular}{|lllll|}
\hline Key TF & Description & $\begin{array}{l}\text { Regulated } \\
\text { gene }\end{array}$ & P-value & FDR \\
\hline DNMT1 & DNA (cytosine-5-)-methyltransferase 1 & RELN, TP53 & 0.00293 & 0.0146 \\
\hline HDAC1 & histone deacetylase 1 & RELN, TP53 & 0.0146 & 0.0366 \\
\hline MYC & $\begin{array}{l}\text { v-myc myelocytomatosis viral oncogene homolog } \\
\text { (avian) }\end{array}$ & KRAS, TP53 & 0.0278 & 0.0464 \\
\hline
\end{tabular}


Table 4

The Kinase target and miRNA target of NUDT21 in LUAD (LinkedOmics).

\begin{tabular}{|llllll|}
\hline Cancer type & Enriched Category & Gene set & Leading Edge Number & $P$-value & FDR \\
\hline LUAD & Kinase Target & Kinase CDK1 & 104 & 0 & 0 \\
\hline & & Kinase ATM & 55 & 0 & 0 \\
\hline \multirow{2}{*}{ miRNA Target } & Kinase PLK1 & 38 & 0 & 0 \\
\hline & ATGTTAA,MIR-302C & 77 & 82 & 0 & 0 \\
\hline & TAGCTTT,MIR-9 & 0 & 0 \\
\hline & TGCTTTG,MIR-330 & 114 & 0 & 0 \\
\hline
\end{tabular}

\subsection{The correlation of genes differentially expressed and NUDT21 in LUAD}

The mRNA sequencing data from 515 patients with LUAD in the TCGA were obtained from the LinkedOmics. As shown in Fig. 9A, the results showed that 19988 genes were closely related to NUDT21. Among them, 11442 genes showed remarkable positive correlations with NUDT21 $(P<0.05)$, while 4387 genes showed significant negative correlations $(P<0.05)$. We also showed the 50 significant genes positively and negatively correlated with NUDT21 in LUAD (Fig. 9B, 9C). Moreover, the expression of NUDT21 had an intense positive association with OGFOD1 (Pearson correlation $=0.5997, P=1.301 \mathrm{e}-51$ ) (Fig. 10A), RSPRY1 (Pearson correlation $=0.5632, P=8.081 \mathrm{e}-48)$ (Fig. 10B), CNOT1 (Pearson correlation $=0.5632, P=1.944 \mathrm{e}-44)$ (Fig. 10C).

\subsection{Immune cell infiltration of NUDT21 in LUAD}

To further reveal the relationship between the immune cell infiltration and NUDT21 in LUAD, we conducted the correlation of them with the TIMER. The expression of NUDT21 was positively associated with the infiltration of CD8 + T cells (Cor $=0.309, P=3.06 \mathrm{e}-12)$, macrophages (Cor $=0.173, P=1.23 \mathrm{e}-4)$, neutrophils (Cor $=0.267, P=2.47 \mathrm{e}-9)$ and dendritic cell (Cor $=0.233, P=25 \mathrm{e}-7)($ Fig. 11).

\subsection{Active compounds of Pinellia ternata and molecular docking}

A total of 116 compounds were found in TCMSP database. Among them, 13 active compounds were retrieved base on $\mathrm{OB}$ and $\mathrm{DL}$ in homeostatic process (Table 5). Besides, to verify the binding ability of active compounds of Pinellia ternata to NUDT21, we conducted molecular docking with the AutoDock Vina. In this analysis, the vina score's value (binding energy) indicates the binding activity between a protein and a compound. The binding energy $\geq-5.0 \mathrm{kcal} / \mathrm{mol}$ was considered the compound and protein with a suitable binding property. Our results showed that baicalein was the best combination with 
NUDT21 (Score $=-8.8 \mathrm{kcal} / \mathrm{mol}$ ) (Fig. 12A). Van der Waals, Pi- cation, conventional-hydrogen bond, Pi-Pi stacked, carbon hydrogen bond, unfavorable donor-donor, and Pi- alkyl were the mainly interacted mode between them (Fig. 12B).

Table 5

The results of screening active components of Pinellia ternata by TCMSP database.

\begin{tabular}{|llcl|}
\hline MOL ID & MOL Name & OB(\%) & DL \\
\hline MOL001755 & 24-Ethylcholest-4-en-3-one & 36.08 & 0.76 \\
\hline MOL002670 & Cavidine & 35.64 & 0.81 \\
\hline MOL002714 & baicalein & 33.52 & 0.21 \\
\hline MOL002776 & Baicalin & 40.12 & 0.75 \\
\hline MOL000358 & beta-sitosterol & 36.91 & 0.75 \\
\hline MOL000449 & Stigmasterol & 43.83 & 0.76 \\
\hline MOL005030 & gondoic acid & 30.7 & 0.2 \\
\hline MOL000519 & coniferin & 31.11 & 0.32 \\
\hline MOL006936 & 10,13-eicosadienoic & 39.99 & 0.2 \\
\hline MOL006937 & 12,13-epoxy-9-hydroxynonadeca-7,10-dienoic acid & 42.15 & 0.24 \\
\hline MOL006957 & (3S,6S)-3-(benzyl)-6-(4-hydroxybenzyl)piperazine-2,5-quinone & 46.89 & 0.27 \\
\hline MOL003578 & Cycloartenol & 38.69 & 0.78 \\
\hline MOL006967 & xanthine-9 & 44.72 & 0.21 \\
\hline
\end{tabular}

\section{Discussion}

NUDT21, as a tumor suppressor gene,which could inhibit the occurrence and development of various cancers, including small cell lung cancer, bladder cancer, and breast cancer. NUDT21 is a 3'-terminal processing factor of mRNA precursor (targeted mRNA precursors 3'contain multiple poly-A splicing sites), regulating mRNA expression through selective alternative polyadenylation [40]. Ultimately, the normal physiological process of NULDT21 was involved in regulating proliferation, differentiation and apoptosis. However, the overexpression of tumor suppressor genes in cancer patients has attracted more and more attention. But the mechanism of them has not yet been elucidated. Studies had found that it might be closely related to genetic alters and DNA methylation [41, 42]. However, the expression and gene regulation network of NUDT21 in patients with LUAD was rarely reported.

In our study, the expression level of NUDT21 and the correlation between differential expression of NUDT21 and pathological stage were first explored in LUAD patients. We found that NUDT21 was up- 
regulated expression in patients with LUAD compared with normal human. In addition, our results showed a significant correlation between the expression of NUDT21 and pathological stage. Furthermore, the survival of LUAD patients with the low expression level of NUDT21 was better prognostic value than LUAD patients with a high expression level of NUDT21. In brief, overexpression of NUDT21 may play an essential role in survival with LUAD patients. Contrary to other studies, NUDT21 was low expressed in varies cancer [43]. To further explore the mechanism of NUDT21 overexpression in LUAD patients, we found that genetic alteration of NUDT21 was high (12\%). Moreover, the promoter methylation level of NUDT21 in LUAD was lower compared to normal human. Therefore, genetic alteration and methylation of NUDT21 may be the leading cause of NUDT21 overexpression. Moreover, NUDT21-neighboring genes (the 50 most frequently altered neighbor genes) were altered at frequencies $>17 \%$ in LUAD. We then explore the potential interactions and function of NUDT21 and its neighboring genes. We found that NUDT21 and its neighboring genes have complex and tight networks of connections. Their primary functions mainly include the regulatory region DNA binding, transcription regulatory region DNA binding, and regulatory region nucleic acid binding. The above evidence reveals that they might affect the processes of gene binding, transcription, and regulation involved in the occurrence and development of cancer.

Moreover, GO enrichment analysis revealed that these genes' functions are mainly connected with inflammatory response caused by the activation of inflammatory factors. As expected, the expression of NUDT21 was positively associated with the immune cell infiltration, including CD $8+T$ cells, macrophages, neutrophils and dendritic cell. Immunotherapy has been recognized as the fourth pillar of cancer therapy, and a large number of preclinical and clinical studies have been revealed the efficacy of immunotherapy for lung cancer [44]. Targeting and regulating the tumor immune microenvironment can divert the immune system to anticancer and increase the sensitivity to established chemotherapy. Chemokines and their receptors are crucial for inflammation and anti-tumor immunity, thus influencing angiogenesis, tumor occurrence, progression, metastasis, therapeutic efficacy, and patient outcomes [4547]. Studies have shown that the $C X C$ family of chemokines and their receptors are associated with tumour metastasis and therapy resistance $[48,49]$. Besides, our results showed that The KEGG pathway of NUDT21 and its neighboring genes involved in the apelin signaling pathway, PI3K-Akt signaling pathway, and axon guidance. Apelin is an endogenous ligand of G protein coupled receptor APJ. It is widely expressed in many tissues, especially the lungs. More and more evidence revealed that the apelin signaling pathway is closely associated with the occurrence of respiratory diseases [50]. Studies have found that inhibiting apelin effectively remodeled the tumor microenvironment, reduced angiogenesis, and effectively inhibited tumor growth [51]. Importantly, apelin prevents resistance to antiangiogenic receptor tyrosine kinase (RTK) inhibitor therapy in lung cancer [51]. PI3K-Akt signaling pathways play a key role in the regulation of cell proliferation, differentiation and apoptosis. AKT is a crucial regulator of cell survival and apoptosis $[52,53]$. AKT is activated by PDK1 through phospholipid binding and activation loop phosphorylation at Thr308 [52, 53]. AKT inhibits apoptosis and promotes survival of malignant cells by phosphorylating and inactivating multiple targets, including Bad, C-Raf and Caspase-9 [54]. In recent years, research has shown that the axon guidance cue molecule Slit2 could suppress lung cancer cell invasion and growth [55]. 
We also focus on their targets and regulators. We then explored the transcription factor targets, kinase targets and miRNA targets of NUDT21 and its neighboring genes, and found that DNMT1, HDAC1, and MYC were their key regulated factor in LUAD. DNMT1 is a major epigenetic enzyme, maintains the genomic stability and the epigenetic state of DNA by copying CpG methylation markers and generating heritable methylation patterns through cell metabolism [56,57]. Approaches for inhibition of DNMT1 may become novel strategies for treating cancers [58]. In recent years, abnormal expression of HDAC1 has been found to have potential clinical prognostic value in various cancers. Studies have shown that downregulation of HDAC1 can inhibit cell proliferation, migration, invasion, angiogenesis and induce cell apoptosis [59]. MYC is a transcription factor that is overexpressed in tumors and participates in preventing immune cells from attacking tumor cells by inducing the expression of PD-L1. MYC expression's role is an alternative marker for evaluation of treatment with non-small cell lung cancer [60]. Therefore, Targeting DNMT1, HDAC1, and MYC may be a promising approach to the treatment of LUAD. We also found that Kinase CDK1, Kinase ATM and Kinase PLK1 were the top three targets in the NUDT21 kinase-target network. Kinase CDK1, Kinase ATM and Kinase PLK1 are involved in DNA repair and progression through the cell cycle. Kinase ATM and RNF8/RNF168 ubiquitin-ligase modify chromatin extensively on the DNA damaged side. In mitosis, phosphorylation of 53BP1 by Kinase PLK1 and Kinase CDK1 impairs the ability of 53BP1 to bind to ubiquitination H2A and locate DNA damage sites properly [61]. The NUDT21 miRNA-target network was associated with MIR-302C, MIR-9, and MIR-330. They are involved in tumor proliferation, differentiation, and invasion. It had been reported that Mir-302C-5P act as a cancer suppressor in a variety of cancers [62]. Moreover, Mir-302c-3p is a tumor suppressor gene of malignant glioma and can be used as a new biomarker to predict glioma patients' clinical prognosis [63]. miR-9 includes three family members, including miR-9-1, miR-9-2 and miR-9-3. Researchers recently found that the promoter region of Mir-9-3 was hypermethylated in lung cancer, leading to the down-regulation of Mir-9-3, and poor prognosis of patients and miR-9 may be a potential lung cancer biomarker [64, 65]. MiR330 acts as a tumor-suppressor microRNA (miRNA) in various cancers and is a promising candidate for miRNA replacement therapy in lung cancer patients [66]. In conclusion, the transcription factor targets, kinase targets and miRNA targets of NUDT21 and its neighboring genes may be potential therapeutic targets and biomarker for LUAD.

Pinellia ternata is a commonly used Chinese medicine for treating infection, inflammation, cough, and vomiting,which had been documented by the Chinese Pharmacopoeia (2015 edition) [21, 22]. However, more and more studies have found that Pinellia ternata has a therapeutic effect on various cancers [23, 24]. Our results found that 13 active compounds of Pinellia ternata were retrieved base on OB and DL from the TCMSP. Among them, baicalein was the best combination with NUDT21 (Score $=-8.8 \mathrm{kcal} / \mathrm{mol}$ ). Hydrogen bonding was their main interaction force (Six hydrogen bonds were found in our study). Baicalein was a bioactive component extracted from various traditional Chinese medicines, including Pinellia ternata and Scutellaria baicalensis Georgi $[67,68]$. In recent years, anti-tumor, anti-inflammatory, and antimicrobial activities of baicalein were found [69]. It had been reported that baicalein could reverse cisplatin resistance of human lung adenocarcinoma A549 cells via PI3K/Akt/NF-KB pathway[70]. 
Although our study has not been further verified the anti-LUAD of baicalein by cells or animal experiments, our results preliminarily indicate that it may affect NUDT21 against LUAD.

In conclusion, by showing the overexpression and gene regulation network of NUDT21 in LUAD, we expect to provide a new perspective on drug selection for clinical workers from the standpoint of immunotherapy for LUAD. Furthermore, identifying new therapeutic targets and prognostic biomarkers to more accurately predicts the survival in patients with LUAD. We also provide potential therapeutic drugs from traditional Chinese medicine in the treatment of LUAD.

\section{Declarations}

\section{Acknowledgements}

The authors are grateful for the data sharing of some publicly available platforms, including cBioPortal, ONCOMINE, GeneMANIA, GEPIA, Metascape, UALCAN, LinkedOmics, Metascape, TIMER, TRRUST, The Human Protein Atlas, and TCMSP.

\section{Author Contributions}

Yong-li SITU performed data analysis work and aided in writing the manuscript. Hong NIE and Zhixin FANG designed the study and assisted in writing the manuscript. Yong-li SITU, Li-na LONG, and Hai-jian LI edited the manuscript. All authors read and approved the final manuscript.

\section{Funding}

This work was supported by Natural Science Foundation of China (No.81673634 and No.81861138042). This funding source had no role in the design of this study and will not have any role during its execution, analyses, interpretation of the data, draft of the manuscript, or decision to submit results.

\section{Availability of data and materials}

The datasets used and analyzed in this study are available from publicly available platforms in the manuscript's method introduction.

\section{Consent to publication}

None.

\section{Ethics approval and consent to participate}

In this study, relevant data were obtained from some publicly available platforms for retrospective analysis. All data in the platform had obtained informed consent signed by the patients or their families and published by relevant institutions or individuals.

\section{Competing interests}


The authors state that there are no conflicts of interest to disclose.

\section{References}

1. Bray F, Ferlay J, Soerjomataram I, Siegel RL, Torre LA, Jemal A. Global cancer statistics 2018: GLOBOCAN estimates of incidence and mortality worldwide for 36 cancers in 185 countries. CA Cancer J Clin. 2018;68(6):394-424. https://doi.org/10.3322/caac.21492. Epub 2018/09/13.

2. Ferlay J, Soerjomataram I, Dikshit R, Eser S, Mathers C, Rebelo M, Parkin DM, Forman D, Bray F. Cancer incidence and mortality worldwide: sources, methods and major patterns in GLOBOCAN 2012. Int J Cancer. 2015;136(5):E359-86. Epub 2014/10/9. https://doi.org/10.1002/ijc.29210.

3. Zheng M. Classification and pathology of lung cancer. Surg Oncol Clin N Am. 2016;25:447-25:4. Epub 2016/07/25. https://doi.org/10.1016/j.soc.2016.02.003.

4. De Stefani E, Brennan P, Boffetta P, Mendilaharsu M, Deneo-Pellegrini $H$, Ronco A, Olivera L, Kasdorf $\mathrm{H}$. Diet and adenocarcinoma of the lung: a case-control study in Uruguay. Lung Cancer. 2002;35(1):43-51. https://doi.org/10.1016/S0169-5002(01)00281-1. Epub 2002/01/01.

5. Aisner DL, Sholl LM, Berry LD, Rossi MR, Chen H, Fujimoto J, Moreira AL, Ramalingam SS, Villaruz LC, Otterson GA, Haura E, Politi K, Glisson B, Cetnar J, Garon EB, Schiller J, Waqar SN, Sequist LV, Brahmer J, Shyr Y, Kugler K, Wistuba II, Johnson BE, Minna JD, Kris MG, Bunn PA, Kwiatkowski DJ. LCMC2 investigators. The impact of smoking and TP53 mutations in lung adenocarcinoma patients with targetable mutations-the lung cancer mutation consortium (LCMC2). Clin Cancer Res. 2018;24(5):1038-47. https://doi.org/10.1158/1078-0432.CCR-17-2289. Epub 2017/12/07.

6. Parry EM, Gable DL, Stanley SE, Khalil SE, Antonescu V, Florea L, Armanios M. Germline Mutations in DNA Repair Genes in Lung Adenocarcinoma. J Thorac Oncol. 2017;12(11):1673-8. https://doi.org/10.1016/j.jtho.2017.08.011. Epub 2017/08/24.

7. Skřičková J, Kadlec B, Venclíček O, Merta Z. Lung cancer. Cas Lek Cesk. 2018 Fall;157(5):226-236. Epub 2018/fall. PMID: 30441934.

8. Saito M, Suzuki H, Kono K, Takenoshita S, Kohno T. Treatment of lung adenocarcinoma by molecular-targeted therapy and immunotherapy. Surg Today. 2018;48(1):1-8. https://doi.org/10.1007/s00595-017-1497-7. Epub 2017/03/09.

9. Maeda R, Yoshida J, Ishii G, Hishida T, Nishimura M, Nagai K. Risk factors for tumor recurrence in patients with early-stage (stage I and II) non-small cell lung cancer: patient selection criteria for adjuvant chemotherapy according to the seventh edition TNM classification. Chest. 2011;140(6):1494-502. https://doi.org/10.1378/chest.10-3279. Epub 2011/05/26.

10. Kris MG, Johnson BE, Berry LD, Kwiatkowski DJ, lafrate AJ, Wistuba II, Varella-Garcia M, Franklin WA, Aronson SL, Su PF, Shyr Y, Camidge DR, Sequist LV, Glisson BS, Khuri FR, Garon EB, Pao W, Rudin C, Schiller J, Haura EB, Socinski M, Shirai K, Chen H, Giaccone G, Ladanyi M, Kugler K, Minna JD, Bunn PA. Using multiplexed assays of oncogenic drivers in lung cancers to select targeted drugs. JAMA. 2014;311(19):1998-2006. https://doi.org/10.1001/jama.2014.3741. Epub 2014/05/21. 
11. Mazières J, Barlesi F, Filleron T, Besse B, Monnet I, Beau-Faller M, Peters S, Dansin E, Früh M, Pless M, Rosell R, Wislez M, Fournel P, Westeel V, Cappuzzo F, Cortot A, Moro-Sibilot D, Milia J, Gautschi O. Lung cancer patients with HER2 mutations treated with chemotherapy and HER2-targeted drugs: results from the European EUHER2 cohort. Ann Oncol. 2016;27(2):281-6. https://doi.org/10.1093/annonc/mdv573. Epub 2015/11/23.

12. Sun M, Ding J, Li D, Yang G, Cheng Z, Zhu Q. NUDT21 regulates 3'-UTR length and microRNAmediated gene silencing in hepatocellular carcinoma. Cancer Lett. 2017;410:158-68. https://doi.org/10.1016/j.canlet.2017.09.026. Epub 2017/09/28.

13. Zheng YS, Chen ML, Lei WD, Zhu SL, You XQ, Liu Y. NUDT21 knockdown inhibits proliferation and promotes apoptosis of pancreatic ductal adenocarcinoma through EIF2 signaling. Exp Cell Res. 2020;395(2):112182. https://doi.org/10.1016/j.yexcr.2020.112182. Epub 2020/07/22.

14. Tan S, Li H, Zhang W, Shao Y, Liu Y, Guan H, Wu J, Kang Y, Zhao J, Yu Q, Gu Y, Ding K, Zhang M, Qian W, Zhu Y, Cai H, Chen C, Lobie PE, Zhao X, Sun J, Zhu T. NUDT21 negatively regulates PSMB2 and CXXC5 by alternative polyadenylation and contributes to hepatocellular carcinoma suppression. Oncogene. 2018;37(35):4887-900. https://doi.org/10.1038/s41388-018-0280-6. Epub 2018/05/21.

15. Xiong M, Chen L, Zhou L, Ding Y, Kazobinka G, Chen Z, Hou T. NUDT21 inhibits bladder cancer progression through ANXA2 and LIMK2 by alternative polyadenylation. Theranostics. 2019;9(24):7156-67. https://doi.org/10.7150/thno.36030. Epub 2019/09/24.

16. Lou JC, Lan YL, Gao JX, Ma BB, Yang T, Yuan ZB, Zhang HQ, Zhu TZ, Pan N, Leng S, Song GJ, Zhang B. Silencing NUDT21 Attenuates the Mesenchymal Identity of Glioblastoma Cells via the NF-KB Pathway. Front Mol Neurosci. 2017;10:420. https://doi.org/10.3389/fnmol.2017.00420. Epub 2017/12/19.

17. Wang BJ, Liu DC, Guo QY, Han XW, Bi XM, Wang H, Wu ZS, Wu WY. NUDT21 Suppresses Breast Cancer Tumorigenesis Through Regulating CPSF6 Expression. Cancer Manag Res. 2020;12:306978. https://doi.org/10.2147/CMAR.S239664. Epub 2020/05/01.

18. Wang H, Hu H, Luo Z, Liu S, Wu W, Zhu M, Wang J, Liu Y, Lu Z. miR-4454 up-regulated by HPV16 E6/E7 promotes invasion and migration by targeting ABHD2/NUDT21 in cervical cancer. Biosci Rep. 2020;40(9):BSR20200796. https://doi.org/10.1042/BSR20200796. Epub 2020/09/30.

19. Li X, Ding J, Wang X, Cheng Z, Zhu Q. NUDT21 regulates circRNA cyclization and ceRNA crosstalk in hepatocellular carcinoma. Oncogene. 2020;39(4):891-904. https://doi.org/10.1038/s41388-0191030-0. Epub 2019/09/30.

20. Zhang L, Zhang W. Knockdown of NUDT21 inhibits proliferation and promotes apoptosis of human K562 leukemia cells through ERK pathway. Cancer Manag Res. 2018;10:4311-23. https://doi.org/10.2147/CMAR.S173496. Epub 2018/10/08.

21. Editiorial Committee of Chinese Pharmacopoeia. Chinese Pharmacopoeia. 2015 ed. Beijing: China Medical Science and Technology Press; 2010. p. 119.(In chinese).

22. Hu Q, Tao SS. The latest progress of study and development on Pinellia ternata. J Southwest Univ Sci Technol. 2005;20:63-8. (In chinese). 
23. Xin XQ, Chen Y, Zhang H, Li Y, Yang MH, Kong LY. Cytotoxic seco-cytochalasins from an endophytic Aspergillus sp. harbored in Pinellia ternata tubers. Fitoterapia. 2019;132:53-9. https://doi.org/10.1016/j.fitote.2018.11.010. Epub 2018/11/26.

24. Li Y, Li D, Chen J, Wang S. A polysaccharide from Pinellia ternata inhibits cell proliferation and metastasis in human cholangiocarcinoma cells by targeting of Cdc42 and 67kDa Laminin Receptor (LR). Int J Biol Macromol. 2016;93(Pt A):520-5. https://doi.org/10.1016/j.ijbiomac.2016.08.069. Epub 2016/08/27.

25. Rhodes DR, Yu J, Shanker K, Deshpande N, Varambally R, Ghosh D, Barrette T, Pandey A, Chinnaiyan AM. ONCOMINE: a cancer microarray database and integrated data-mining platform. Neoplasia. 2004;6(1):1-6. https://doi.org/10.1016/S1476-5586(04)80047-2. Epub 2004/01.

26. Chandrashekar DS, Bashel B, Balasubramanya SAH, Creighton CJ, Ponce-Rodriguez I, Chakravarthi BVSK, Varambally S. UALCAN: A Portal for Facilitating Tumor Subgroup Gene Expression and Survival Analyses. Neoplasia. 2017;19(8):649-58. https://doi.org/10.1016/j.neo.2017.05.002. Epub 2017/07/18.

27. Tang Z, Li C, Kang B, Gao G, Li C, Zhang Z. GEPIA: a web server for cancer and normal gene expression profiling and interactive analyses. Nucleic Acids Res. 2017;45(W1):W98-102. Epub 2017/04/12. https://doi.org/10.1093/nar/gkx247.

28. Gao J, Aksoy BA, Dogrusoz U, Dresdner G, Gross B, Sumer SO, Sun Y, Jacobsen A, Sinha R, Larsson E, Cerami E, Sander C, Schultz N. Integrative analysis of complex cancer genomics and clinical profiles using the cBioPortal. Sci Signal. 2013;6(269):pl1. https://doi.org/10.1126/scisignal.2004088. Epub 2013/04/02.

29. Szklarczyk D, Gable AL, Lyon D, Junge A, Wyder S, Huerta-Cepas J, Simonovic M, Doncheva NT, Morris JH, Bork P, Jensen LJ, Mering CV. STRING v11: protein-protein association networks with increased coverage, supporting functional discovery in genome-wide experimental datasets. Nucleic Acids Res. 2019;47(D1):D607-13. Epub 2019/01/08. https://doi.org/10.1093/nar/gky1131.

30. Warde-Farley D, Donaldson SL, Comes O, Zuberi K, Badrawi R, Chao P, Franz M, Grouios C, Kazi F, Lopes CT, Maitland A, Mostafavi S, Montojo J, Shao Q, Wright G, Bader GD, Morris Q. The GeneMANIA prediction server: biological network integration for gene prioritization and predicting gene function. Nucleic Acids Res. 2010;38(Web Server issue):W214-20. Epub 2010/06/21. https://doi.org/10.1093/nar/gkq537.

31. Zhou Y, Zhou B, Pache L, Chang M, Khodabakhshi AH, Tanaseichuk O, Benner C, Chanda SK. Metascape provides a biologist-oriented resource for the analysis of systems-level datasets. Nat Commun. 2019;10(1):1523. https://doi.org/10.1038/s41467-019-09234-6. Epub 2019/04/03.

32. Han H, Cho JW, Lee S, Yun A, Kim H, Bae D, Yang S, Kim CY, Lee M, Kim E, Lee S, Kang B, Jeong D, Kim Y, Jeon HN, Jung H, Nam S, Chung M, Kim JH, Lee I. TRRUST v2: an expanded reference database of human and mouse transcriptional regulatory interactions. Nucleic Acids Res. 2018;46(D1):D380-6. https://doi.org/10.1093/nar/gkx1013. Epub 2018/01/04. 
33. Vasaikar SV, Straub P, Wang J, Zhang B. LinkedOmics: analyzing multi-omics data within and across 32 cancer types. Nucleic Acids Res. 2018;46(D1):D956-63. Epub 2018/01/04. https://doi.org/10.1093/nar/gkx1090.

34. Li T, Fan J, Wang B, Traugh N, Chen Q, Liu JS, Li B, Liu XS. TIMER: A Web Server for Comprehensive Analysis of Tumor-Infiltrating Immune Cells. Cancer Res. 2017;77(21):e108-10. doi:10.1158/00085472.CAN-17-0307. Epub 2017/11/01.

35. Ru J, Li P, Wang J, Zhou W, Li B, Huang C, Li P, Guo Z, Tao W, Yang Y, Xu X, Li Y, Wang Y, Yang L. TCMSP: a database of systems pharmacology for drug discovery from herbal medicines. $J$ Cheminform. 2014;6:13. doi:10.1186/1758-2946-6-13. Epub 2014/04/16.

36. Trott O, Olson AJ. AutoDock Vina: improving the speed and accuracy of docking with a new scoring function, efficient optimization, and multithreading. J Comput Chem. 2010;31(2):455-61. https://doi.org/10.1002/jcc.21334. Epub 2010/01/30.

37. Yamagata N, Shyr Y, Yanagisawa K, Edgerton M, Dang TP, Gonzalez A, Nadaf S, Larsen P, Roberts JR, Nesbitt JC, Jensen R, Levy S, Moore JH, Minna JD, Carbone DP. A training-testing approach to the molecular classification of resected non-small cell lung cancer. Clin Cancer Res. 2003;9(13):4695704. Epub 2003/10/15. PMID: 14581339.

38. Okayama H, Kohno T, Ishii Y, Shimada Y, Shiraishi K, Iwakawa R, Furuta K, Tsuta K, Shibata T, Yamamoto S, Watanabe S, Sakamoto H, Kumamoto K, Takenoshita S, Gotoh N, Mizuno H, Sarai A, Kawano S, Yamaguchi R, Miyano S, Yokota J. Identification of genes upregulated in ALK-positive and EGFR/KRAS/ALK-negative lung adenocarcinomas. Cancer Res. 2012;72(1):100-11. https://doi.org/10.1158/0008-5472.CAN-11-1403. Epub 2011/11/11.

39. Landi MT, Dracheva T, Rotunno M, Figueroa JD, Liu H, Dasgupta A, Mann FE, Fukuoka J, Hames M, Bergen AW, Murphy SE, Yang P, Pesatori AC, Consonni D, Bertazzi PA, Wacholder S, Shih JH, Caporaso NE, Jen J. Gene expression signature of cigarette smoking and its role in lung adenocarcinoma development and survival. PLoS One. 2008;3(2):e1651. https://doi.org/10.1371/journal.pone.0001651. Epub 2008/02/20.

40. Gao CC, Xu QQ, Xiao FJ, Wang H, Wu CT, Wang LS. NUDT21 suppresses the growth of small cell lung cancer by modulating GLS1 splicing. Biochem Biophys Res Commun. 2020;526(2):431-8. https://doi.org/10.1016/j.bbrc.2020.03.089. Epub 2020/05/28.

41. Yasuda M, Kuwano $H$, Watanabe $M$, Toh $Y$, Ohno S, Sugimachi K. p53 expression in squamous dysplasia associated with carcinoma of the oesophagus: evidence for field carcinogenesis. $\mathrm{Br} \mathrm{J}$ Cancer. 2000;83(8):1033-8. https://doi.org/10.1054/bjoc.2000.1443. Epub 2000/09/19.

42. Ma HS, Wang EL, Xu WF, Yamada S, Yoshimoto K, Qian ZR, Shi L, Liu LL, Li XH. Overexpression of DNA (Cytosine-5)-Methyltransferase 1 (DNMT1) And DNA (Cytosine-5)-Methyltransferase 3A (DNMT3A) Is Associated with Aggressive Behavior and Hypermethylation of Tumor Suppressor Genes in Human Pituitary Adenomas. Med Sci Monit. 2018;24:4841-50. https://doi.org/10.12659/MSM.910608. Epub 2018/07/13. 
43. Chu Y, Elrod N, Wang C, Li L, Chen T, Routh A, Xia Z, Li W, Wagner EJ, Ji P. Nudt21 regulates the alternative polyadenylation of Pak1 and is predictive in the prognosis of glioblastoma patients. Oncogene. 2019;38(21):4154-68. https://doi.org/10.1038/s41388-019-0714-9. Epub 2019/01/31.

44. Sa H, Ma K, Gao Y, Wang D. Predictive value of tumor mutation burden in immunotherapy for lung cancer. Zhongguo Fei Ai Za Zhi. 2019;22(6):380-4. https://doi.org/10.3779/j.issn.10093419.2019.06.08. Epub 2019/06/20.

45. Nagarsheth $\mathrm{N}$, Wicha MS, Zou W. Chemokines in the cancer microenvironment and their relevance in cancer immunotherapy. Nat Rev Immunol. 2017;17(9):559-72. https://doi.org/10.1038/nri.2017.49. Epub 2017/05/30.

46. Atretkhany KN, Drutskaya MS, Nedospasov SA, Grivennikov SI, Kuprash DV. Chemokines, cytokines and exosomes help tumors to shape inflammatory microenvironment. Pharmacol Ther. 2016;168:98-112. https://doi.org/10.1016/j.pharmthera.2016.09.011. Epub 2016/09/06.

47. Chow MT, Luster AD. Chemokines in cancer. Cancer Immunol Res. 2014;2(12):1125-31. https://doi.org/10.1158/2326-6066.CIR-14-0160. Epub 2014/12/01.

48. Waugh DJ, Wilson C. The interleukin-8 pathway in cancer. Clin Cancer Res. 2008;14(21):6735-41. Epub 2008/11/01. https://doi.org/10.1158/1078-0432.CCR-07-4843.

49. Tokunaga R, Zhang W, Naseem M, Puccini A, Berger MD, Soni S, McSkane M, Baba H, Lenz HJ. CXCL9, CXCL10, CXCL11/CXCR3 axis for immune activation - A target for novel cancer therapy. Cancer Treat Rev. 2018;63:40-7. https://doi.org/10.1016/j.ctrv.2017.11.007. Epub 2017/11/26.

50. Yan J, Wang A, Cao J, Chen L. Apelin/APJ system: an emerging therapeutic target for respiratory diseases. Cell Mol Life Sci. 2020;77(15):2919-30. https://doi.org/10.1016/j.ctrv.2017.11.007. Epub 2017/11/26.

51. Uribesalgo I, Hoffmann D, Zhang Y, Kavirayani A, Lazovic J, Berta J, Novatchkova M, Pai TP, Wimmer RA, László V, Schramek D, Karim R, Tortola L, Deswal S, Haas L, Zuber J, Szűcs M, Kuba K, Dome B, Cao Y, Haubner BJ, Penninger JM. Apelin inhibition prevents resistance and metastasis associated with anti-angiogenic therapy. EMBO Mol Med. 2019;11(8):e9266. https://doi.org/10.15252/emmm.201809266. Epub 2019/06/24.

52. Hopkins BD, Parsons RE. Molecular pathways: intercellular PTEN and the potential of PTEN restoration therapy. Clin Cancer Res. 2014;20:5379-83. https://doi.org/10.1158/1078-0432.CCR-132661. Epub 2014/11/01.

53. Song MS, Salmena L, Pandolfi PP. The functions and regulation of the PTEN tumour suppressor. Nat Rev Mol Cell Biol. 2012;13:283-96. https://doi.org/10.1038/nrm3330. Epub 2012/04/04.

54. Yang $M$, Wang $H$, Zhou M, Liu W, Kuang P, Liang H, Yuan Q. The natural compound sulforaphene, as a novel anticancer reagent, targeting PI3K-AKT signaling pathway in lung cancer. Oncotarget. 2016;7(47):76656-66. https://doi.org/10.18632/oncotarget.12307. Epub 2016/11/22.

55. Lin YY, Yang CH, Sheu GT, Huang CY, Wu YC, Chuang SM, Fann MJ, Chang H, Lee H, Chang JT. A novel exon 15-deleted, splicing variant of Slit2 shows potential for growth inhibition in addition to 
invasion inhibition in lung cancer. Cancer. 2011;117(15):3404-15.

https://doi.org/10.1002/cncr.25890. Epub 2011/01/24.

56. Haruta M, Shimada M, Nishiyama A, Johmura Y, Le Tallec B, Debatisse M, Nakanishi M. Loss of maintenance DNA methylation results in abnormal DNA origin firing during DNA replication. Biochem Biophys Res Commun. 2016;469(4):960-6. https://doi.org/10.1016/j.bbrc.2015.12.090. Epub 2016/01/22.

57. Nishiyama A, Yamaguchi L, Nakanishi M. Regulation of maintenance DNA methylation via histone ubiquitylation. J Biochem. 2016;159:9-15. https://doi.org/10.1093/jb/mvv113. Epub 2015/11/20.

58. Chen Y, Tang Q, Xiao Q, Yang L, Hann SS. Targeting EP4 downstream c-Jun through ERK1/2mediated reduction of DNMT1 reveals novel mechanism of solamargine-inhibited growth of lung cancer cells. J Cell Mol Med. 2017;21(2):222-33. https://doi.org/10.1111/jcmm.12958. Epub 2016/09/13.

59. Zhang L, Bu L, Hu J, Xu Z, Ruan L, Fang Y, Wang P. HDAC1 knockdown inhibits invasion and induces apoptosis in non-small cell lung cancer cells. Biol Chem. 2018;399(6):603-10.

https://doi.org/10.1515/hsz-2017-0306. Epub 2018/05/24.

60. Kim EY, Kim A, Kim SK, Chang YS. MYC expression correlates with PD-L1 expression in non-small cell lung cancer. Lung Cancer. 2017;110:63-7. https://doi.org/10.1016/j.lungcan.2017.06.006. Epub 2017/06/14.

61. Benada J, Burdová K, Lidak T, von Morgen P, Macurek L. Polo-like kinase 1 inhibits DNA damage response during mitosis. Cell Cycle. 2015;14(2):219-31.

https://doi.org/10.4161/15384101.2014.977067. Epub 2015/01/21.

62. Ye JJ, Cheng YL, Deng JJ, Tao WP, Wu L. LncRNA LINC00460 promotes tumor growth of human lung adenocarcinoma by targeting miR-302c-5p/FOXA1 axis. Gene. 2019;685:76-84. https://doi.org/10.1016/j.gene.2018.10.058. Epub 2018/10/22.

63. Zheng GD, Wang YU, Zhu XD. Evaluation of miR-302c-3p as prognostic biomarkers in glioma patients. Eur Rev Med Pharmacol Sci. 2016;20(8):1521-5. Epub 2016/04/01. PMID: 27160124.

64. Heller G, Weinzierl M, Noll C, Babinsky V, Ziegler B, Altenberger C, Minichsdorfer C, Lang G, Döme B, End-Pfützenreuter A, Arns BM, Grin Y, Klepetko W, Zielinski CC, Zöchbauer-Müller S. Genome-wide miRNA expression profiling identifies miR-9-3 and miR-193a as targets for DNA methylation in nonsmall cell lung cancers. Clin Cancer Res. 2012;18(6):1619-29. https://doi.org/10.1158/10780432.CCR-11-2450. Epub 2012/03/15.

65. Sromek M, Glogowski M, Chechlinska M, Kulinczak M, Szafron L, Zakrzewska K, Owczarek J, Wisniewski P, Wlodarczyk R, Talarek L, Turski M, Siwicki JK. Changes in plasma miR-9, miR-16, miR205 and miR-486 levels after non-small cell lung cancer resection. Cell Oncol (Dordr). 2017;40(5):529-36. https://doi.org/10.1007/s13402-017-0334-8. Epub 2017/06/20.

66. Mohammadi A, Mansoori B, Duijf PHG, Safarzadeh E, Tebbi L, Najafi S, Shokouhi B, Sorensen GL, Holmskov U, Baradaran B. Restoration of miR-330 expression suppresses lung cancer cell viability, 
proliferation, and migration. J Cell Physiol. 2021;236(1):273-83. https://doi.org/10.1002/jcp.29840. Epub 2020/06/24.

67. Seo CS, Shin HK. HPLC-PDA method for simultaneous determination of nine marker components in banhasasim-tang. J Chromatogr Sci. 2016;54(3):299-304.

https://doi.org/10.1093/chromsci/bmv141. Epub 2015/09/08.

68. Su H, Song S, Yan X, Fang L, Zeng B, Zhu Y. Endogenous salicylic acid shows different correlation with baicalin and baicalein in the medicinal plant Scutellaria baicalensis Georgi subjected to stress and exogenous salicylic acid. PLoS One. 2018;13(2):e0192114.

https://doi.org/10.1371/journal.pone.0192114. Epub 2018/02/13.

69. Zhao Z, Liu B, Sun J, Lu L, Liu L, Qiu J, Li Q, Yan C, Jiang S, Mohammadtursun N, Ma W, Li M, Dong J, Gong W. Scutellaria Flavonoids Effectively Inhibit the Malignant Phenotypes of Non-small Cell Lung Cancer in an Id1-dependent Manner. Int J Biol Sci. 2019;15(7):1500-13. https://doi.org/10.7150/ijbs.33146. Epub 2019/06/02.

70. Yu M, Qi B, Xiaoxiang W, Xu J, Liu X. Baicalein increases cisplatin sensitivity of A549 lung adenocarcinoma cells via PI3K/Akt/NF-KB pathway. Biomed Pharmacother. 2017;90:677-85. https://doi.org/10.1016/j.biopha.2017.04.001. Epub 2017/04/14.

\section{Figures}




\begin{tabular}{|c|c|}
\hline Analysis type by cancer & $\begin{array}{l}\text { Cancer } \\
\text { vs. } \\
\text { normal } \\
\text { NUDT21 }\end{array}$ \\
\hline Bladder cancer & \\
\hline Brain and CNS cancer & 1 \\
\hline Breast cancer & 1 \\
\hline Cervical cancer & 1 \\
\hline Colorectal cancer & 3 \\
\hline Esophageal cancer & \\
\hline Gastric cancer & 1 \\
\hline Head and neck cancer & 2 \\
\hline Kidney cancer & 2 \\
\hline Leukemia & 1 \\
\hline Liver cancer & \\
\hline Lung cancer & 9 \\
\hline Lymphoma & 2 \\
\hline Melanoma & 1 \\
\hline Myeloma & \\
\hline Other cancer & 4 \\
\hline Ovarian cancer & \\
\hline Pancreatic cancer & 1 \\
\hline Prostate cancer & \\
\hline Sarcoma & 1 \\
\hline Significant unigue analyses & 23 \\
\hline Total unique analyses & 323 \\
\hline
\end{tabular}

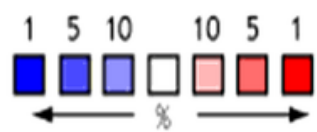

Figure 1

mRNA levels of NUDT21 in lung cancer (ONCOMINE). The figure shows the numbers of datasets with statistically significant mRNA over-expression (red) or downregulated expression (blue) of NUDT21. 
A Expression of NUDT21 in LUAD based on sample types

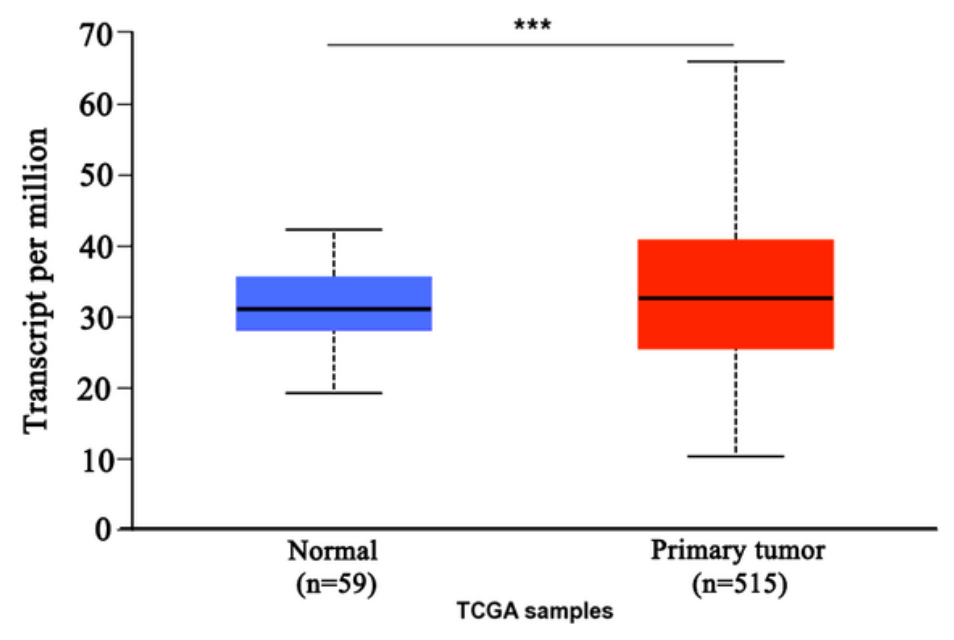

B Expression of NUDT21 in LUAD based on patient's gender

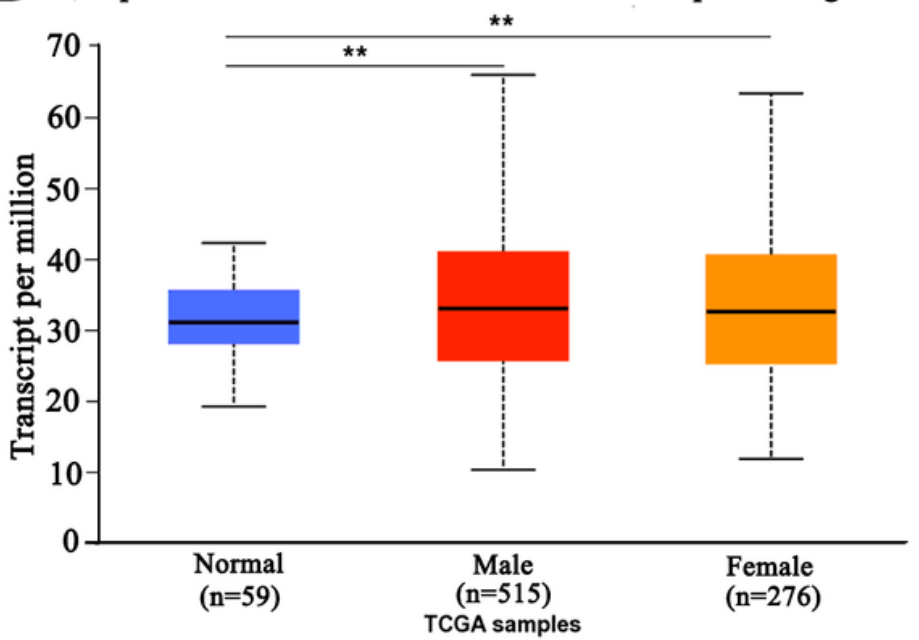

C Expression of NUDT21 in LUAD based on individual cancer stages

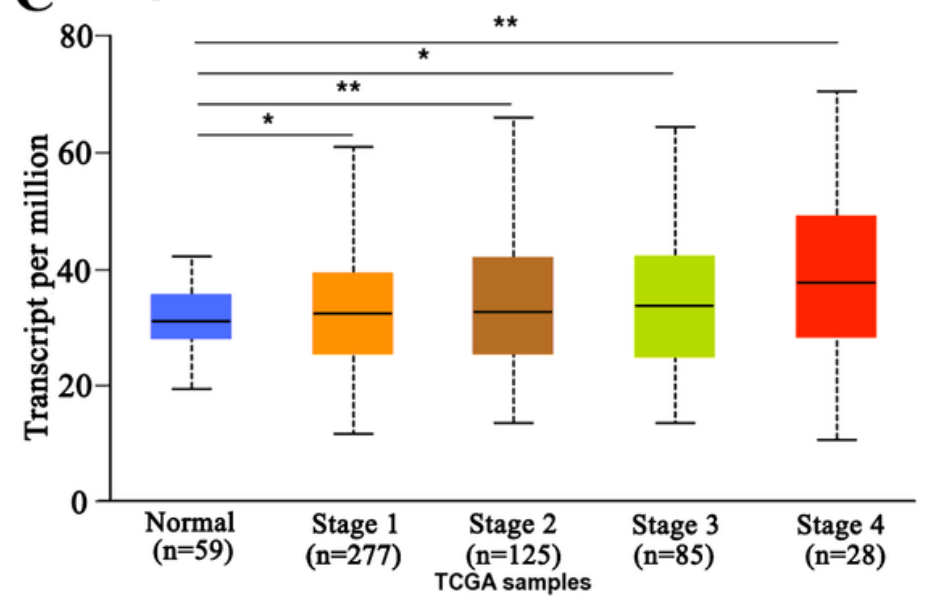

Figure 2

The transcription levels of NUDT21 in LUAD (UALCAN). A. Boxplot showing relative expression of NUDT21 in normal and LUAD samples. B. Boxplot showing relative expression of LUAD of either gender in normal individuals and LUAD patients. C. Boxplot showing relative expression of NUDT21 of stages in normal individuals and LUAD patients. Data are mean \pm SE. *, $P<0.05 ; * \star, P<0.01 ; * \star \star, P<0.001$. 


\section{LUAD}

NUDT21

\section{Figure 3}

The relative level of NUDT21 in LUAD (GEPIA).
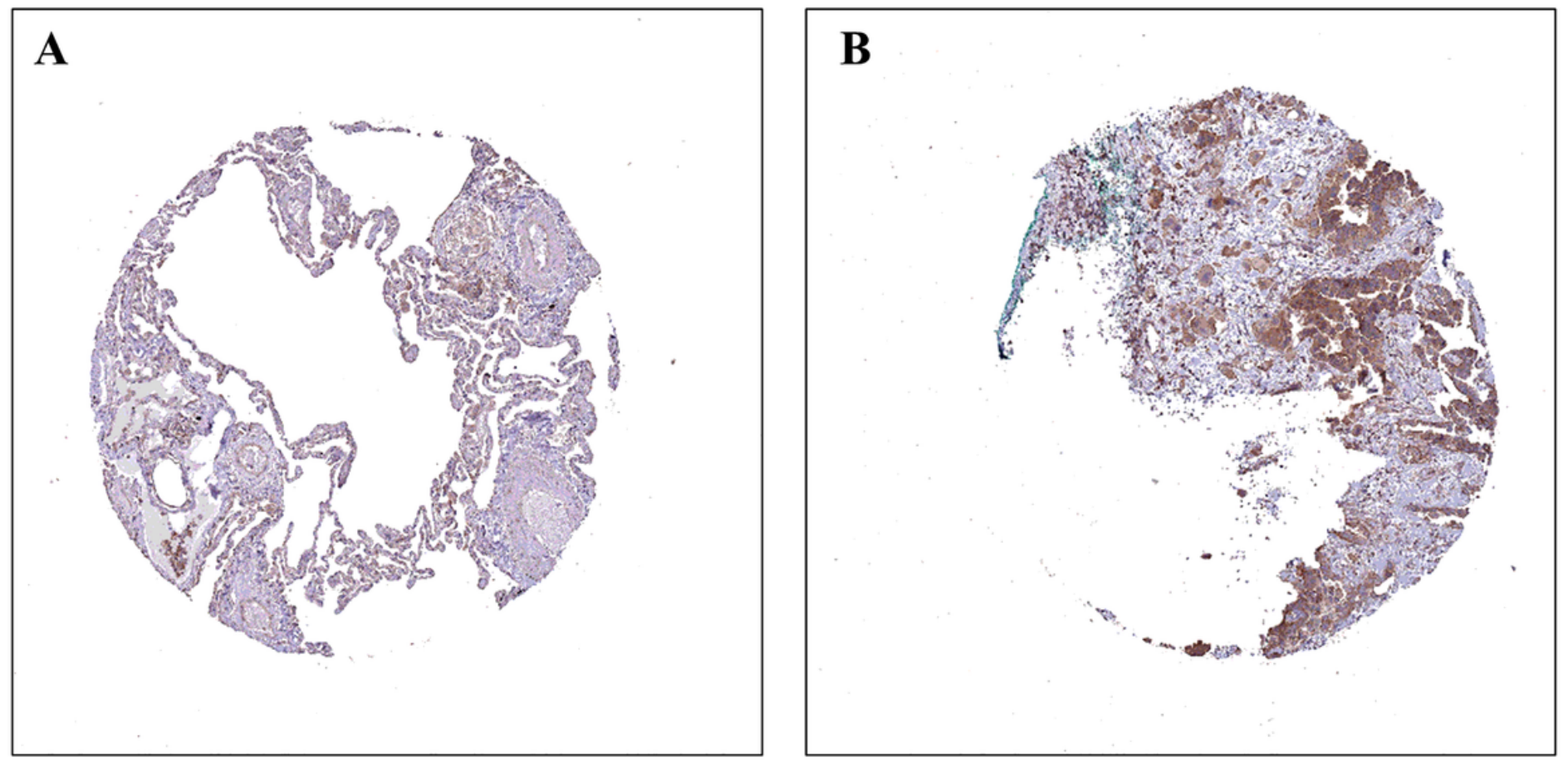

\section{Figure 4}

The protein expression of NUDT21 in LUAD tissue (The Human Protein Atlas). The protein expression of NUDT21 in (A) normal lung tissue, (B) LUAD tissue. 


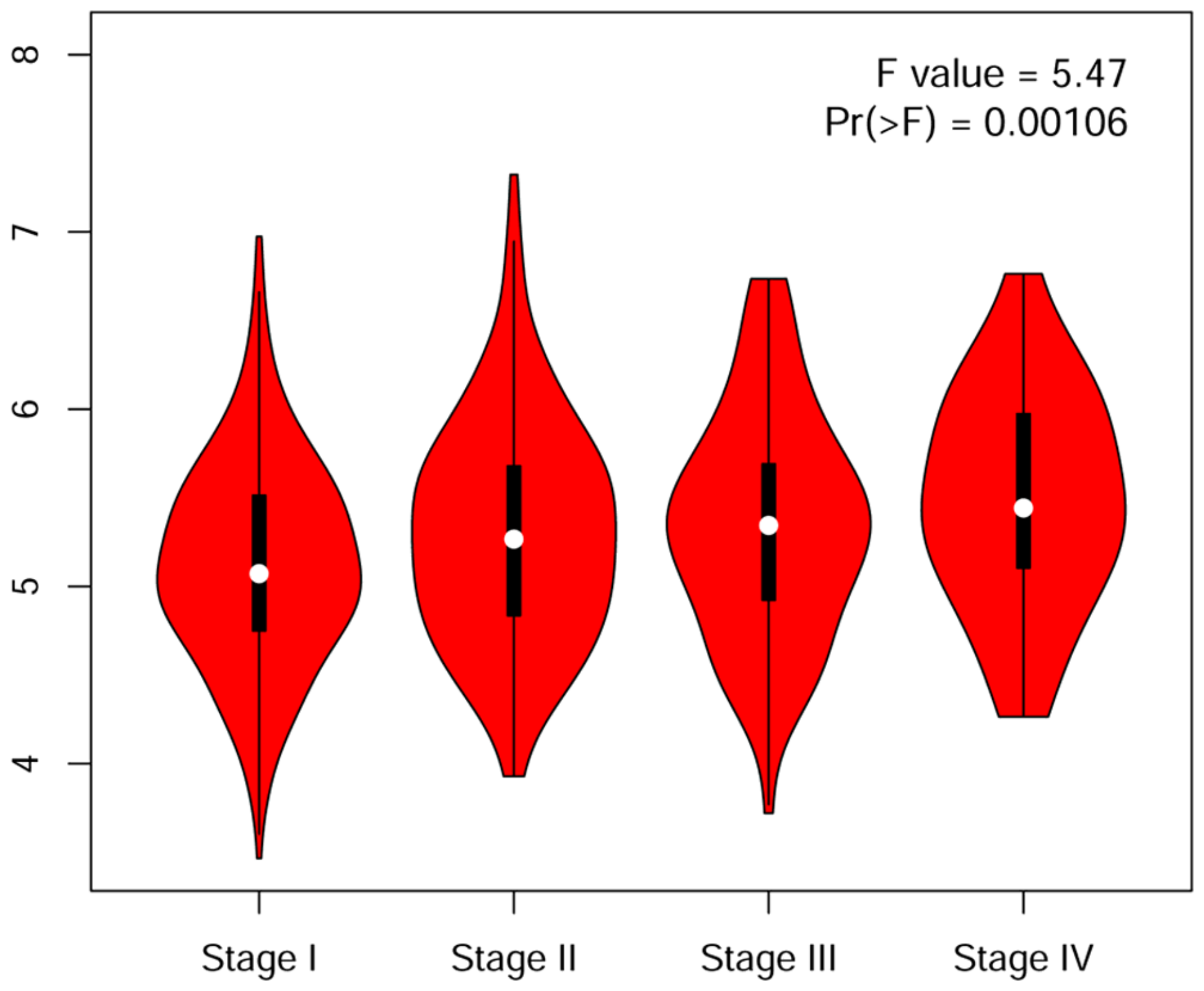

Figure 5

Correlation between the expression level of NUDT21 and the pathological stage in LUAD (GEPIA). ${ }^{*} \mathrm{P}<$ 0.05 . 


\section{Overal survival}

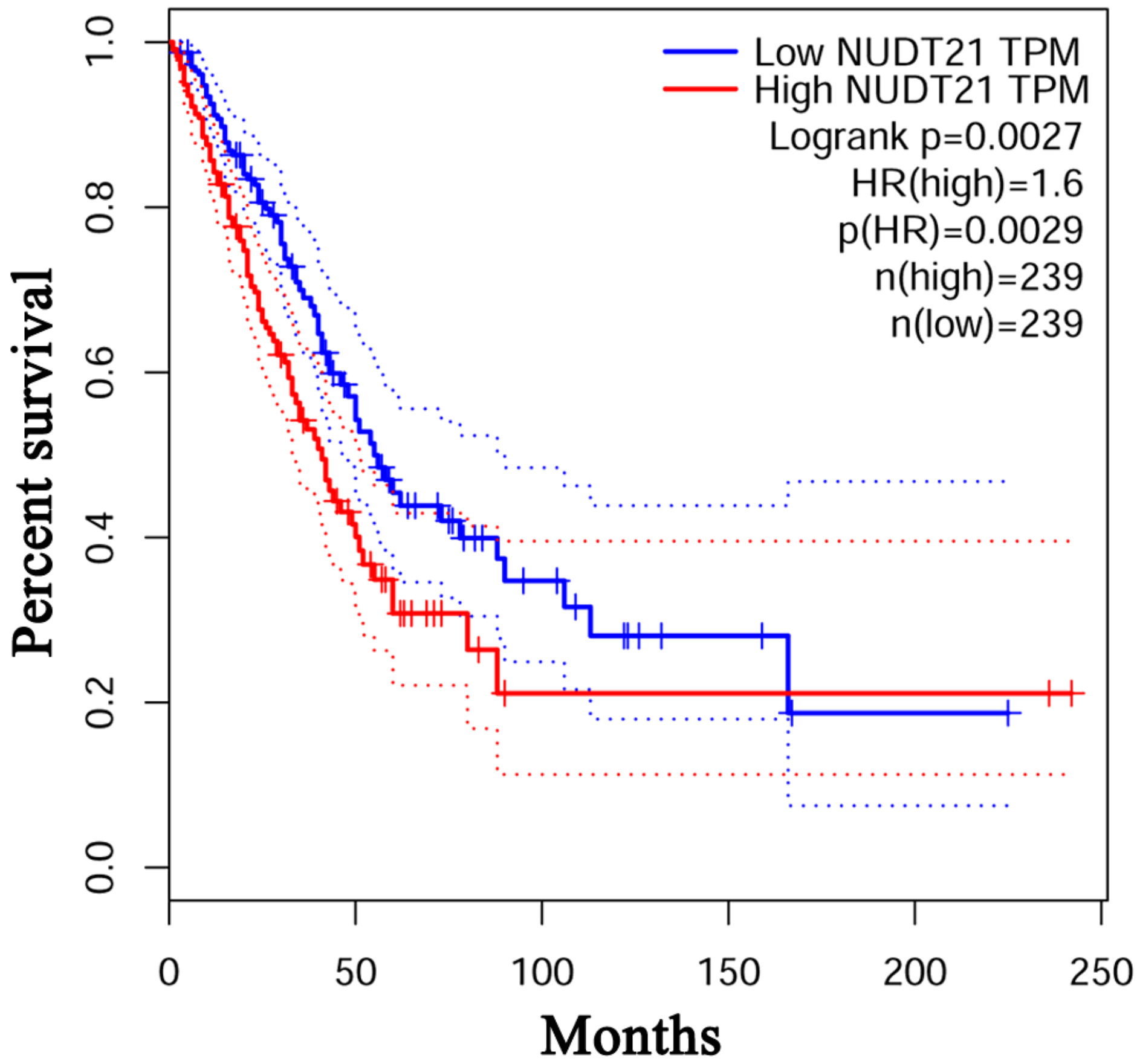

Figure 6

The prognostic value of NUDT21 in LUAD patients in the overall survival curve (GEPIA). 
A

\section{Altered in $28(12 \%)$ of 230 patients} NUDT21 $12 \%$ ||

Genetic Alteration

|Amplification Deep Deletion IImRNA High ImRNA Low No alterations

C

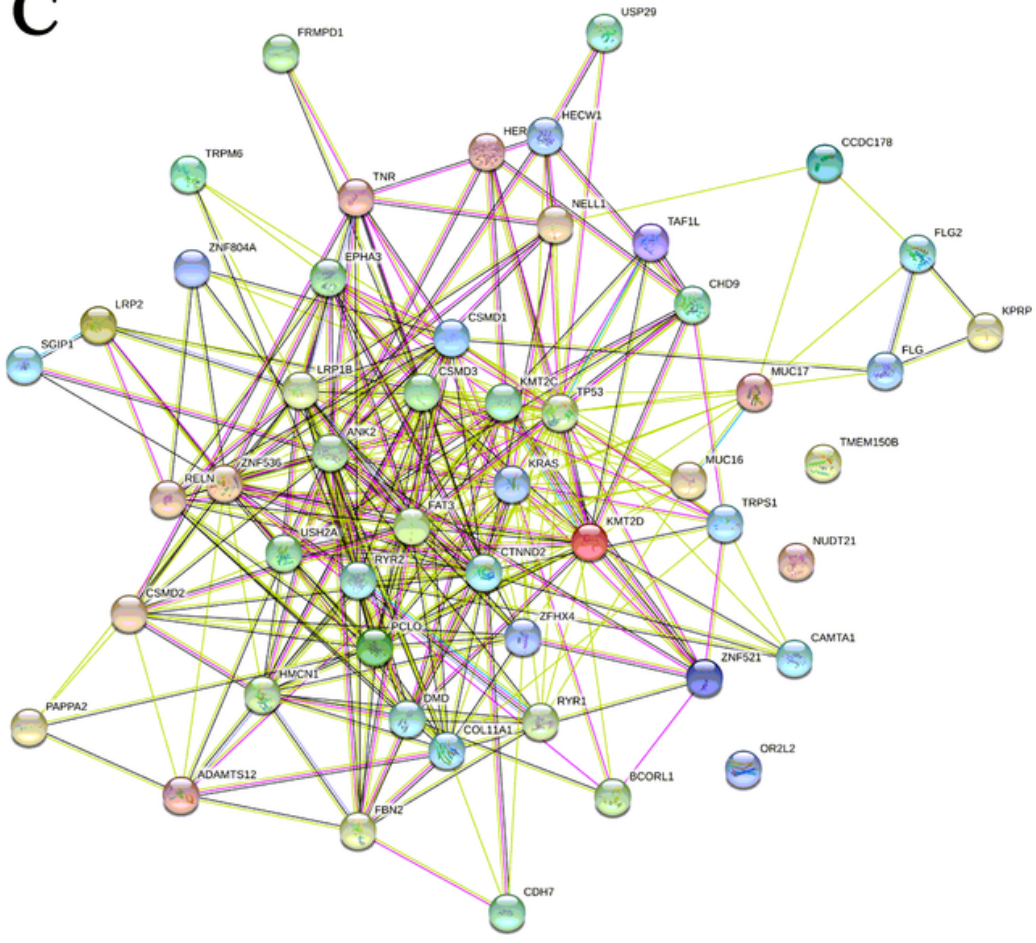

B

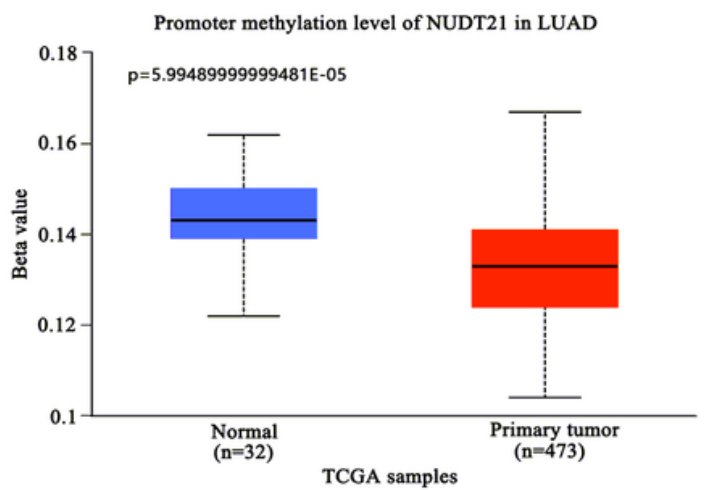

D

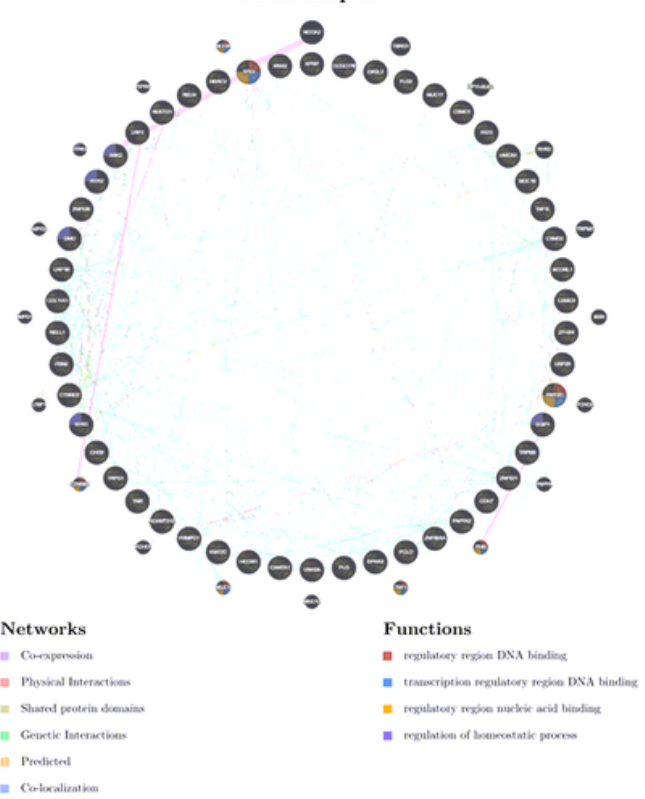

Figure 7

Genetic alteration, and interaction analyses of NUDT21 in LUAD. (A) Summary of alterations in NUDT21 in LUAD. (B) Protein-protein interaction network of NUDT21 and the top 50 neighbor altered gene. (C)Function analyses of NUDT21 and the top 50 neighbor altered gene 
A

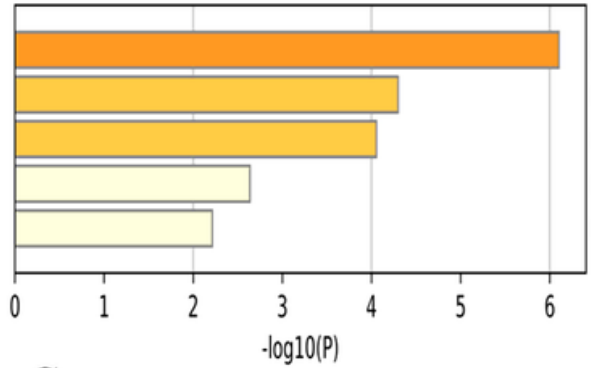

C

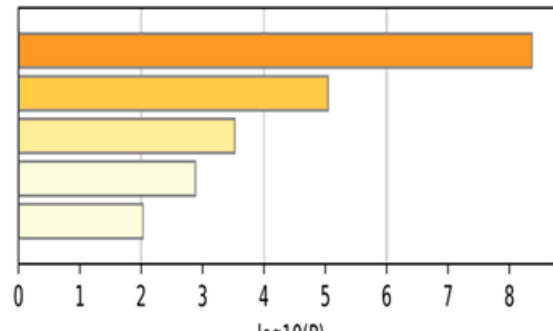

E

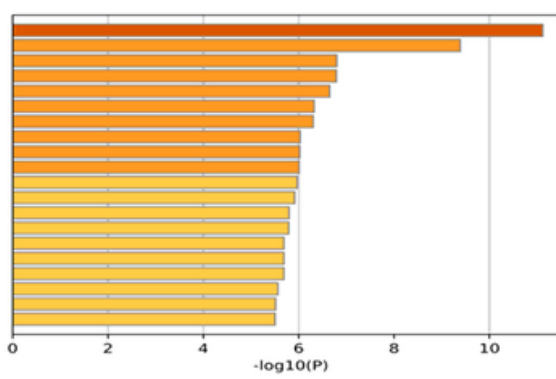

B

60:0031012: extracellular matrix 60:0016324: apical plasma membrane 60:0030018: Z disc 60:0005938: cell cortex 60:0098794: postsynapse

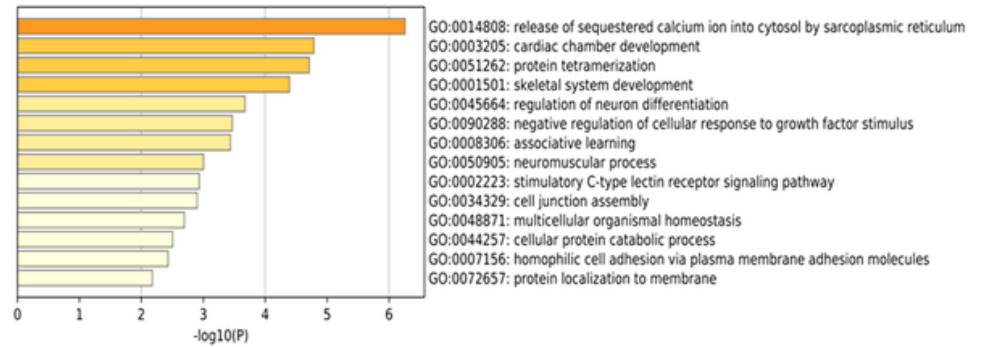

D 60:0005509: calcium ion binding 60:0005198: structural molecule activity 60:0019904: protein domain specific bindin 60:0005262: calcium channel activity 60:0042393: histone binding hsa04371: Apelin signaling pathway k004151: PI3K-Akt signaling pathway hsa04360: Axon guidance

\section{Figure 8}

GO function and KEGG pathways enrichment analysis of NUDT21 and the top 50 neighbor altered gene in LUAD (metascape). (A) Cellular components. (B) Biological processes. (C) Molecular functions. (D) KEGG pathway analysis. (E) Disease.
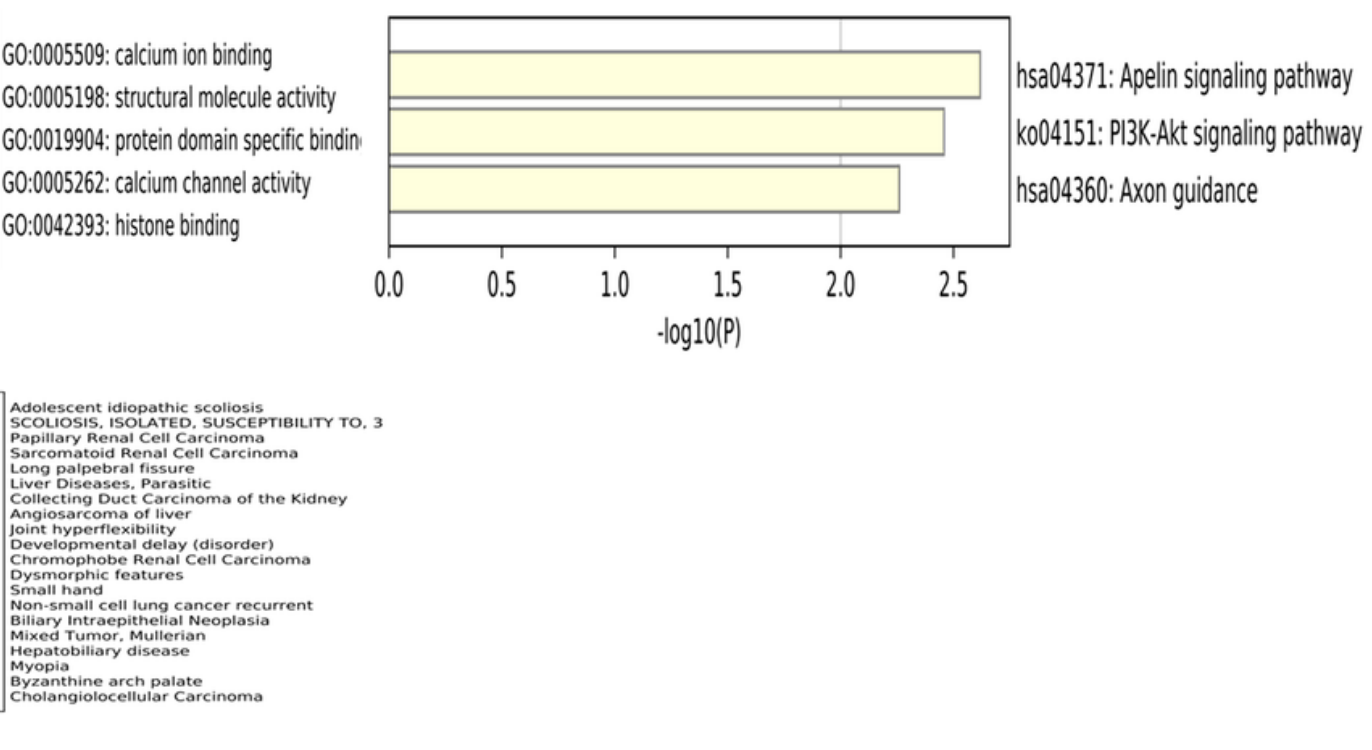
A NUDT21 Association Result

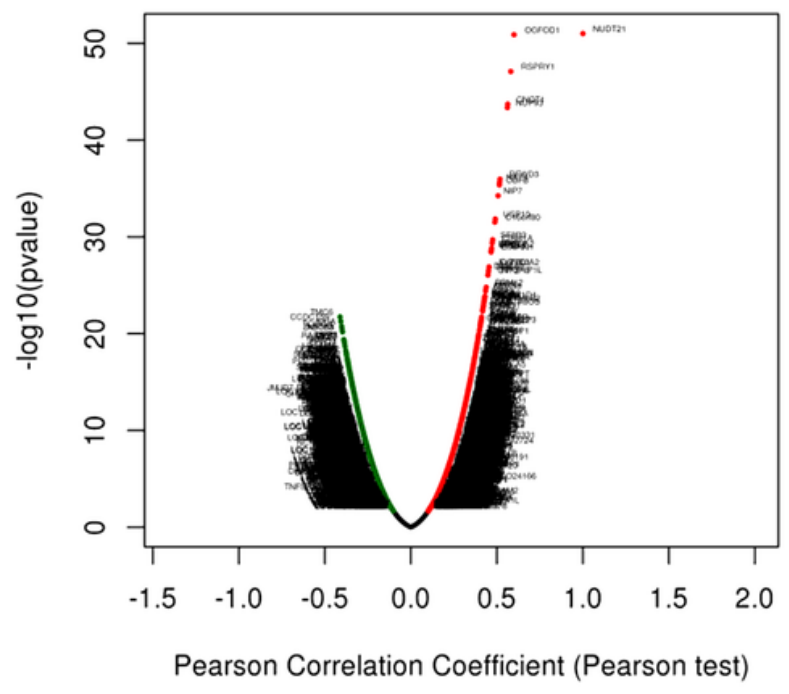

$\mathrm{C}$

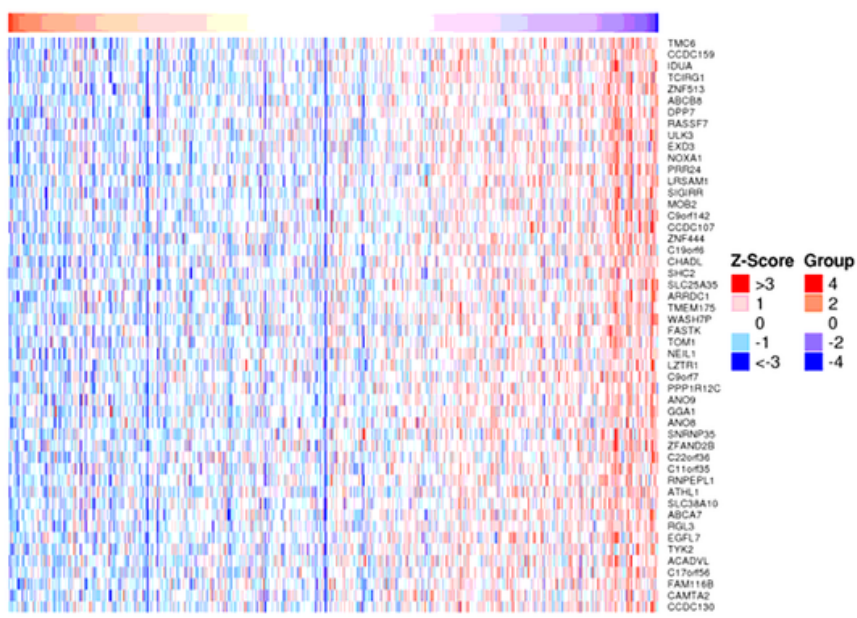

B

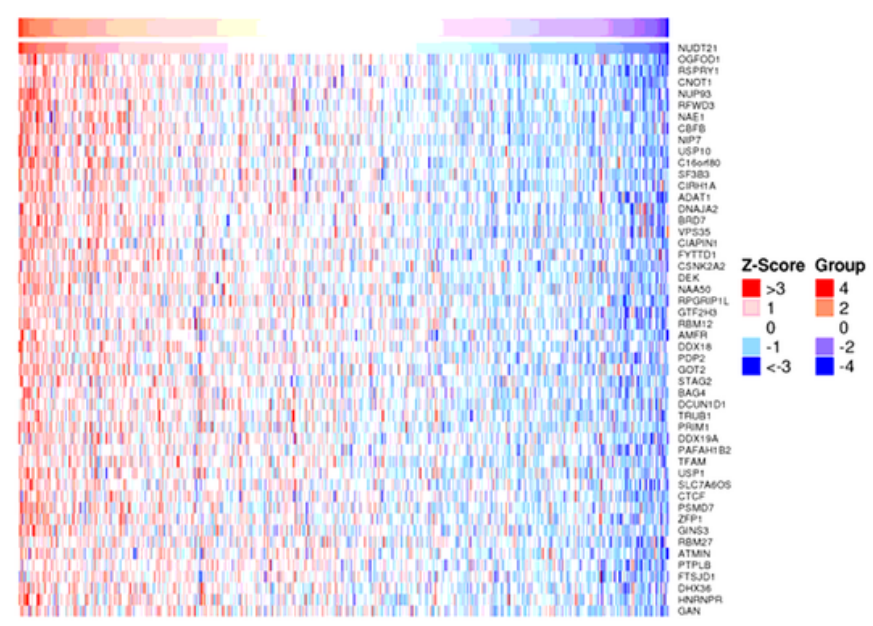

Figure 9

Genes differentially expressed in correlation with NUDT21 in LUAD (LinkedOmics). (A) A Pearson test was used to analyze correlations between NUDT21 and genes differentially expressed in LUAD. (B and C) Heat maps showing genes positively and negatively correlated with NUDT21 in LUAD (TOP 50). Red indicates positively correlated genes and blue indicates negatively correlated genes. 

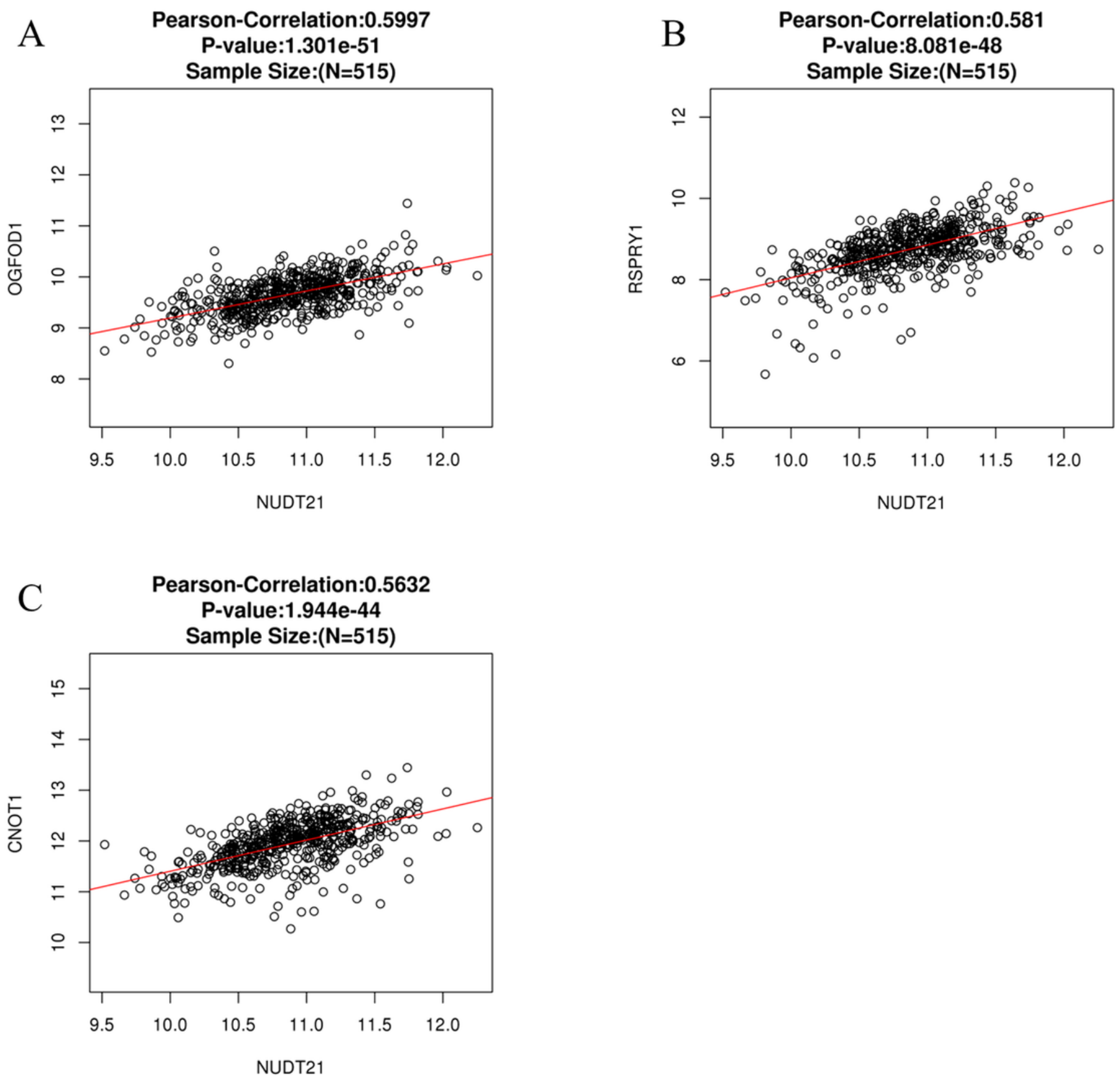

Figure 10

Gene expression correlation analysis of NUDT21 in LUAD (LinkedOmics). The scatter plot shows Pearson correlation of NUDT21 expression with expression of OGFOD1 (A), RSPRY1 (B), CNOT1 (C) in LUAD. 

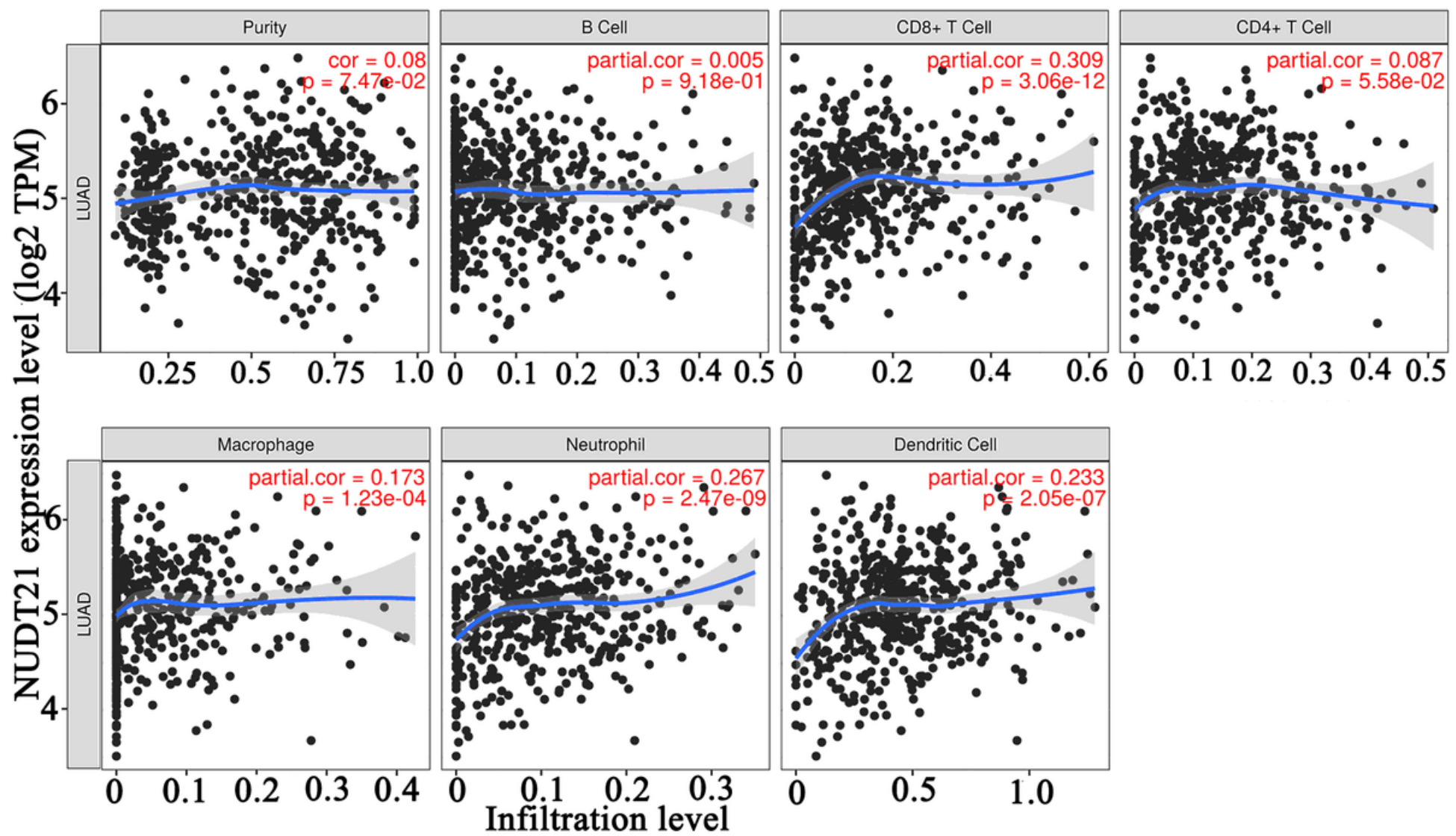

Figure 11

The correlation between NUDT21 and immune cell infiltration in LUAD (TIMER).
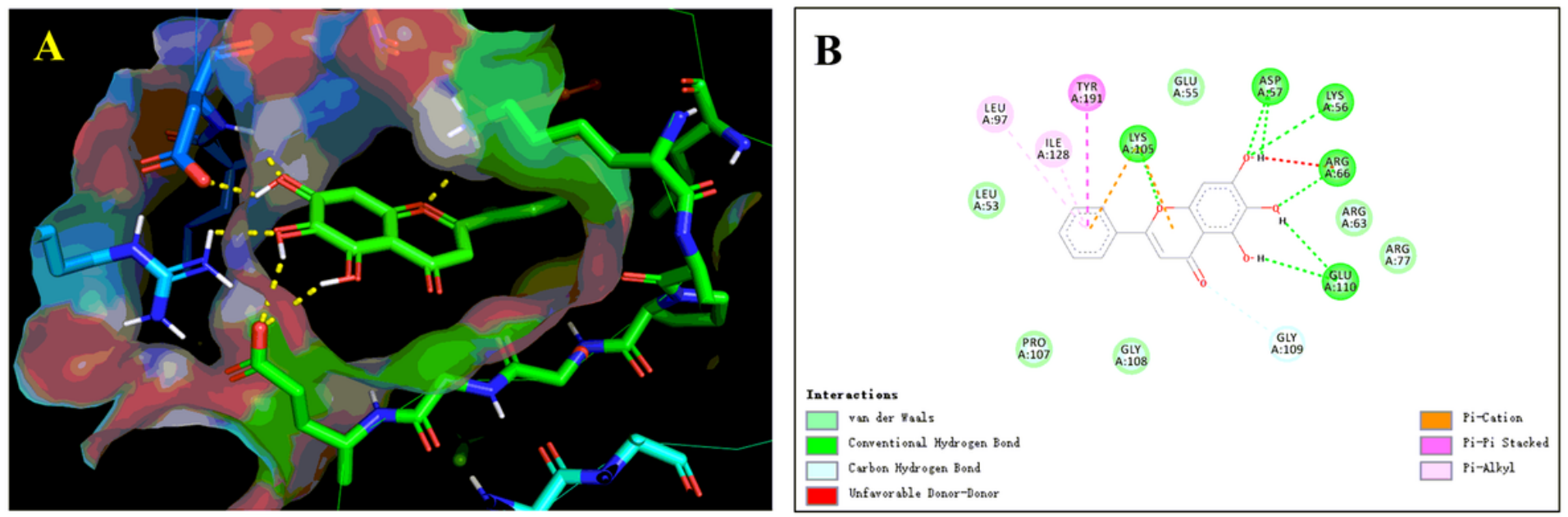

Figure 12

Molecular docking models of NUDT21 with baicalein. A. Molecular docking of NUDT21 with baicalein; B. 2D diagram of receptor-ligand interactions (NUDT21 and baicalein). 